\title{
DISTRIBUIÇÃO EM PROFUNDIDADE DOS ELEMENTOS \\ QUÍMICOS EM LIXIVIADOS DE MANTO DE ALTERAÇÃO \\ ARENO SILTO-ARGILOSO CONTAMINADO POR VINHAÇA
}

\section{DISTRIBUTION OF CHEMICAL ELEMENTS IN LEACHATES COLLECTED ALONG CLAYEY-SILTY SAND SOIL PROFILE CONTAMINATED BY VINASSE}

\author{
Sueli Yoshinaga Pereira ${ }^{1}$; Nathália Pozzi Arcaro ${ }^{1}$; Bruno César Mortatti ${ }^{1}$; Miriam \\ Gonçalves Miguel $^{1}$
}

Artigo recebido em: 05/12/2011 e aceito para publicação em: 09/03/2012

\begin{abstract}
Leachates of soils contaminated by vinasse in Serra Azul (SP) were studied aiming to identify water soluble and geochemically reactive elements, which could infiltrate and modify the groundwater composition. A 24 meter-depth borehole was drilled in a 20 year-old deactivated vinasse dam; soil samples were collected at one meter interval. The soil was classified as clayey - silty sand. Soil leachates presented distribution along soil profile according to oxidation-reduction (from shallower to deeper depths) environments. Values of electrical conductivity, concentrations of $\mathrm{K}$ and $\mathrm{F}$ had increased along the soil profile; $\mathrm{Cr}, \mathrm{Co}, \mathrm{Ni}, \mathrm{Sr}, \mathrm{Sn}$ and $\mathrm{Pb}$ presented an opposite behavior. Thus soil leachates could provide information about chemicals elements distribution and their behavior along the contaminated profile.
\end{abstract}

Keywords: Vinasse. Soil contamination. Serra Azul. Guarani Aquifer.

Resumo: Lixiviados de solo contaminado por vinhaça em Serra Azul (SP) foram estudados visando identificar elementos solúveis ou reativos geoquimicamente, que poderiam infiltrar e modificar a composição da água subterrânea. Uma sondagem de 24 metros de profundidade foi perfurada dentro de um tanque de vinhaça desativado há 20 anos; amostras de solo foram coletadas a cada metro. O solo foi classificado como areno silto-argiloso. Lixiviados do solo apresentaram distribuição ao longo do perfil de acordo com os ambientes de oxidação - redução (da menor para maior profundidade). Valores de condutividade elétrica, e concentrações de K e F cresceram ao longo do perfil do solo; $\mathrm{Cr}, \mathrm{Co}, \mathrm{Ni}, \mathrm{Sr}, \mathrm{Sn}$ e $\mathrm{Pb}$ apresentaram comportamento inverso. Assim, lixiviados de solo puderam proporcionar informações sobre a distribuição dos elementos químicos e seu comportamento ao longo do perfil contaminado.

Palavras Chave: Vinhaça. Contaminação do solo. Serra Azul. Aquifero Guarani.

\section{INTRODUÇÃO}

A vinhaça é um subproduto do etanol (álcool), butanol e aguardente (RESENDE, 1984), resultado da destilação e fermentação da cana de açúcar no processo de fabricação de álcool, também podendo originar-se como subproduto da produção de açúcar, sendo eliminada no processo de cristalização do caldo da cana. A vinhaça é caracterizada como efluente de destilarias com alto poder poluente e alto valor fertilizante. Este efluente apresenta alto teor de matéria orgânica, baixo $\mathrm{pH}$, elevada corrosividade e altos índices de demanda bioquímica de oxigênio (DBO), além de elevada temperatura na saída dos destiladores (CORTEZ et al., 1998).

O aumento na produção de álcool reflete no aumento da produção de vinhaça, que resulta em uma grande quantidade desse efluente. Em
1986, foi estimada a relação 1:12 entre álcool e vinhaça, ou seja a cada litro de álcool produzido, é gerado 12 litros de vinhaça (GLOEDEN et al., 1991; HASSUDA, 1989).

Esta proporção pode variar de forma significativa; há a possibilidade da variação de 10 a 15 litros de vinhaça para cada litro de etanol (CORTEZ et al., 1998).

A vinhaça disposta em áreas de sacrifício e em lagoas sem impermeabilização, e utilizada na fertirrigação de lavouras, eram os modos de disposição comuns na década de 80 e início da década de 90. Apesar de muitos estudos realizados e medidas de proibição relacionadas às formas de disposição altamente poluidoras, não houve adoção de medidas de remediação ou contenção destas áreas contaminadas.

\footnotetext{
${ }^{1}$ UNICAMP.(sueliyos@ige.unicamp.br, napozzi@hotmail.com, bcmortatti@hotmail.com, mgmiguel@ fec.unicamp.br)
} 
O objetivo do presente artigo foi conhecer a distribuição e os comportamentos químicos de solo contaminado por vinhaça em profundidade, dentro de um antigo tanque de vinhaça sem impermeabilização. $\mathrm{O}$ antigo tanque de vinhaça funcionou desde a década de 1980 até o ano de 2004, quando o principal uso do solo foi a plantação de cana de açúcar com fertirrigação. Esta plantação foi finalizada na área para a implantação da reforma agrária, que originou o Assentamento Rural
Sepé Tiarajú. Os ensaios de lixiviação visaram identificar quais elementos são prontamente solúveis e geoquimicamente reativos com a água, que percola e modifica a composição físico-química das águas subterrâneas.

A área de estudo está situada no município de Serra Azul (Figura 1), a 300 km da capital São Paulo. Nesta área ocorre o Sistema Aquifero Guarani, que possui índices de vulnerabilidade de moderada a alta.

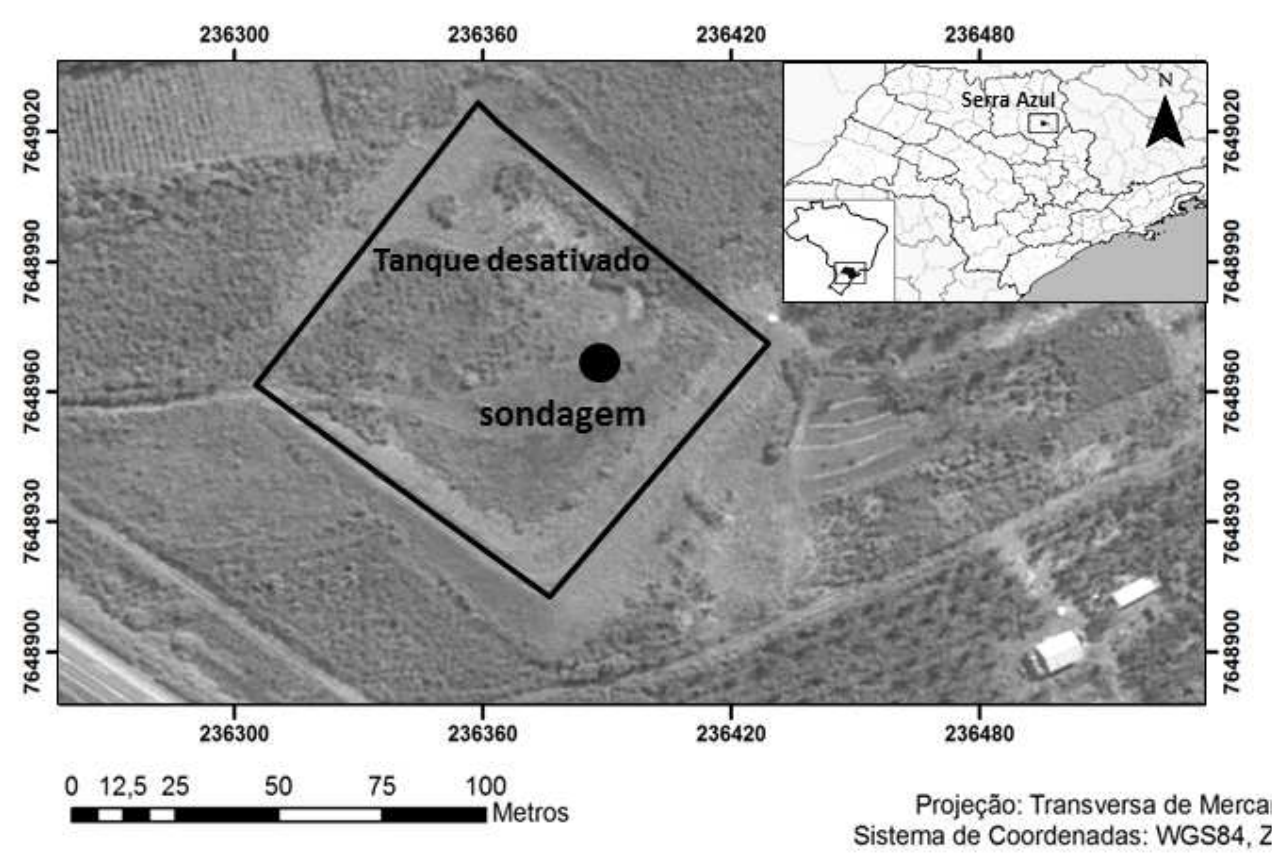

Figura 1 - Local da área de estudo.

Figure 1 - Local of the study area.

\section{MATERIAIS E MÉTODOS}

$\mathrm{Na}$ área interna do antigo tanque de vinhaça foi realizada uma sondagem de prospecção a trado (SPT) de acordo com a norma técnica brasileira NBR 8604 da Associação Brasileira de Normas Técnicas (ABNT, 1986), porém sem leituras de resistência à penetração. A profundidade alcançada foi de 24 metros até chegar ao nível d'água (do mês de agosto de 2009) e a rocha sã (arenito). Este solo está sobreposto aos arenitos da Formação Botucatu e Pirambóia, que forma o Sistema Aquifero Guarani. As amostras de solo foram coletadas de metro em metro; na ocorrência de solos com texturas mais finas, a amostragem foi realizada em intervalos menores. Assim, foram coletadas adicionalmente amostras nas profundidades de $1,7 \mathrm{~m}$, $9,5 \mathrm{~m}$ e $10,7 \mathrm{~m}$, totalizando 27 amostras deste perfil de solo. As amostras de solo foram acondicionadas em sacos plásticos e levadas ao laboratório, onde sofreram homogeneização e quarteamento. As amostras mais representativas do perfil de solo foram separadas para a análise granulométrica e físico-química de solo e para os ensaios de lixiviação.

\section{Caracterização física do solo}

As amostras mais representativas de solo foram separadas para a caracterização física, no Laboratório de Mecânica de Solos e Estradas da Faculdade de Engenharia Civil da Universidade Estadual de Campinas (FEC - UNICAMP). As amostras de solo representativas das profundidades de 2 a 3 metros, 6 a 7 metros, 9,5 a 10 metros, 12 a 13 metros, 15 a 16 metros, 18 a 19 metros, 20 a 21 metros, e 23 a 24 metros foram selecionadas para a análise granulométrica, segundo a NBR 7181/1984 (ABNT 1984), com e sem o uso de defloculante 
(dispersante químico) na fase de sedimentação do ensaio de granulometria conjunta. $\mathrm{O}$ peneiramento foi dividido em dois diferentes tipos: fino, selecionaram-se frações do solo que passam na peneira de $2,0 \mathrm{~mm}$ e ficam retidos na peneira de $0,075 \mathrm{~mm}$; e o grosso, para frações que ficam retidas na peneira de $2,0 \mathrm{~mm}$, contabilizando os pedregulhos. No caso, foi utilizado o material separado pelo peneiramento fino, uma vez que a quantidade de material retido na peneira de $2,0 \mathrm{~mm}$ foi insignificante. Os ensaios de peneiramento foram realizados para partículas com diâmetros equivalentes entre $2,0 \mathrm{~mm}$ e $0,075 \mathrm{~mm}$ de diâmetro como também ensaios de sedimentação em água destilada para partículas menores que $0,075 \mathrm{~mm}$. Para que as partículas finas do material não se agreguem e possam atuar de modo individual durante a sedimentação foi usada $45,7 \mathrm{~g}$ de hexametafosfato de sódio em 1 litro de água destilada em parte do material. Sendo assim foram realizados dois ensaios de sedimentação simultâneos (com e sem o uso de defloculante) para cada amostra. A solução defloculante usada foi a de $45,7 \mathrm{~g}$ de hexametafosfato de sódio em 1 litro de água destilada.

\section{Caracterização química do solo e de seu lixivia- do}

As 27 amostras de solo foram separadas para a análise por fluorescência de raio X (FRX) e para as análises do lixiviado. A porção de solo encaminhada para a FRX sofreu moagem, e foi disposta em pastilha prensada para análise química por espectrometria de fluorescência de raios $\mathrm{X}$, Philips, modelo PW 2404, do Laboratório de Geoquímica Analítica do Instituto de Geociências (IG-UNICAMP). Para o controle de qualidade dos resultados, duas amostras de materiais de referência internacional (GSS-2 e GSS-5) foram analisadas em paralelo. Os elementos maiores e menores (exceto $\mathrm{Na}_{2} \mathrm{O}, \mathrm{MgO}, \mathrm{CaO}$ e $\mathrm{K}_{2} \mathrm{O}$ ) foram determinados com o programa Uniquant, para análises semiquantitativas em FRX, e os demais elementos foram determinados com o programa Solo2010 - Superq, para análises quantitativas.

Ainda, a determinação da percentagem de perda a $105^{\circ} \mathrm{C}$ e percentagem de perda ao fogo $(\% \mathrm{PF})$ à $1000^{\circ} \mathrm{C}$ foram executadas de acordo com o método de Potts (1992). Uma porção da amostra sofreu lixiviação conforme método desenvolvido por Hageman (2007). O lixiviado resultante foi analisado para determinação dos íons maiores (lítio, cálcio, magnésio, sódio, potássio, amônio, fluoreto, nitrato, nitrito, brometo, fosfato, sulfato e cloreto) por cromatografia de íons pelo equipamento Dionex ICS 2500. Medidas de pH,
Eh $(\mathrm{mV})$ e condutividade elétrica (microSiemens por centímetro) foram realizadas. $\mathrm{O}$ Eh foi corrigido para o potencial padrão do hidrogênio (Standard hydrogen electrode - SHE) de acordo com a equação 1:

Eh $=$ Ehmedido $+209-0,7 *\left(t-25^{\circ} \mathrm{C}\right) m V$, onde (Equação 1)

$209 \mathrm{mV}$ é o potencial do eletrodo de referência e 0,7 é um fator de correção, função da temperatura de aquisição do Eh (NORDSTROM e WILDE, 1998).

Nos testes de lixiviação para íons maiores, em 50 gramas de amostras de solo foi adicionado um litro de água deionizada, e agitado por $10 \mathrm{mi}-$ nutos em centrífuga. As medidas de $\mathrm{pH}$, Eh e condutividade elétrica foram feitas em seguida. Após filtragem por filtro de $0,45-\mu \mathrm{m}$, estas amostras foram levadas para análise de cátions e ânions por cromatografia de íons no Laboratório de Geoquímica Analítica do IG-UNICAMP. A água deionizada utilizada para a lixiviação também foi analisada. As demais porções das amostras de solo sofreram lixiviação por ácido nítrico para determinação de metais por ICP-MS Xseries ${ }^{I I}$ (Thermo) equipado com CCT (Collision Cell Technology) para atenuação de interferentes. Todas as soluções foram preparadas com água ultra-pura $(18,2$ $\mathrm{M} \Omega . \mathrm{cm}$ ), obtida por sistema Milli-Q. O ácido nítrico $\left(\mathrm{HNO}_{3}\right)$ foi purificado por sub-ebulição. Os frascos utilizados para as diluições foram previamente limpos com $\mathrm{HNO}_{3} 5 \%$ e enxaguados com água ultra-pura. Para extração $2 \mathrm{~g}$ de cada amostra foram pesados em tubos de centrífuga de $50 \mathrm{~mL}$. A cada amostra foi adicionado $40 \mathrm{~mL}$ de água ou $\mathrm{HNO}_{3} 1 \%$ para extração com agitação manual por 5 minutos seguida de centrifugação a $5.000 \mathrm{rpm}$ por 10 minutos. Após a extração com $\mathrm{HNO}_{3} 1 \%$, uma alíquota de $10 \mathrm{~mL}$ do extrato obtido recebeu a adição de $150 \mu \mathrm{L}$ da solução contendo os padrões internos (In e Re, cada um com 200 ppb) para correção do drift instrumental. Para as amostras extraídas com água uma alíquota de $9,5 \mathrm{~mL}$ foi combinada com $0,5 \mathrm{~mL}$ de $\mathrm{HNO}_{3} 20 \%$ após receber os padrões internos como descrito acima. A adição do $\mathrm{HNO}_{3} 20 \%$ visa acidificar a alíquota para $1 \%$ para determinação no ICP-MS. A amostra correspondente ao intervalo 5 a $6 \mathrm{~m}$, extraída com água teve de ser filtrada, pois apresentou material em suspensão. Adicionalmente, a mesma amostra extraída com $\mathrm{HNO}_{3}$ foi analisada com e sem filtração; a semelhança dos resultados mostrou que a extração com ácido dispensa a etapa de filtração. Algumas amostras foram analisadas duas vezes para verificar a precisão das determinações. 


\section{Análises}

Os resultados foram colocados em planilhas eletrônicas e gráficos. Os valores de $\mathrm{pH}$ e Eh foram dispostos em diagramas de $\mathrm{pH}$ e Eh para diversos elementos e ambientes para interpretação e análises. Uma análise estatística de correlação (Pearson - r) em matriz entre todas as variáveis analisadas foram feitas, no sentido de avaliar as possíveis relações entre os parâmetros físicos e químicos dos resultados dos lixiviados.

Os resultados dos lixiviados foram comparados aos resultados de FRX do solo para validar, em termos quantitativos, a disponibilidade dos elementos prontamente solúveis no solo que poderiam passar para o lixiviado.
Por fim, uma discussão foi elaborada e comparada com os resultados encontrados na literatura científica.

\section{RESULTADOS \\ Caracterização Física do solo}

A Figura 2 apresenta as curvas granulométricas das oito amostras de solos coletadas dentro do tanque, com (CD) e sem (SD) o uso de defloculante na fase de sedimentação dos ensaios granulométricos. A Tabela 1 mostra os valores das frações granulométricas dessas amostras em função da profundidade.

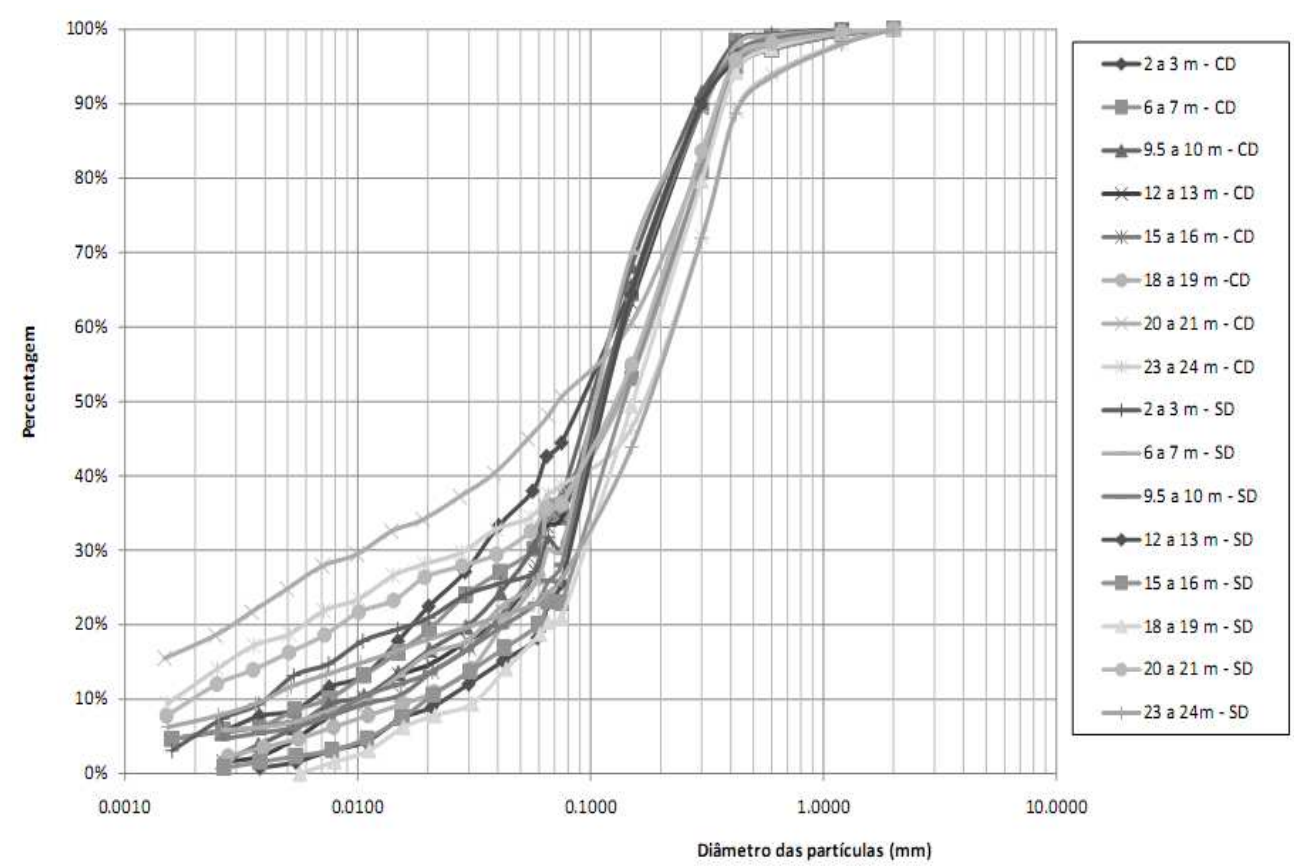

Figura 2 - Curvas granulométricas das amostras de solos do perfil coletado no tanque, com (CD) e sem (SD) o uso de defloculante.

Figure 2 - Grain-size distribution curves of soils samples collected in the dam, with dispersant (CD) and without dispersant (SD). 
Tabela 1 - Valores de frações granulométricas das amostras em profundidade. Table 1 - Grain-size fractions of the soil samples with depth.

\begin{tabular}{|cccccccc|}
\hline \multirow{2}{*}{$\begin{array}{c}\text { Profundidade } \\
(\mathrm{m})\end{array}$} & Cor & \multicolumn{3}{c}{ Com Defloculante } & \multicolumn{3}{c|}{ Sem Defloculante } \\
& & Argila & Silte & Areia & Argila & Silte & Areia \\
\hline $2-3$ & Vermelho & 22,0 & 21,1 & 57,0 & 18,7 & 25,7 & 55,7 \\
$6-7$ & Vermelho & 20,6 & 24,0 & 55,3 & 14,3 & 27,3 & 58,4 \\
$9,5-10$ & Vermelho & 25,1 & 24,6 & 50,3 & 20,5 & 21,0 & 58,5 \\
$12-13$ & Cinza amarelado & 18,9 & 25,6 & 55,5 & 16,4 & 21,2 & 62,5 \\
$15-16$ & Cinza amarelado & 19,0 & 24,4 & 56,5 & 15,9 & 23,9 & 60,2 \\
$18-19$ & Cinza amarelado & 15,0 & 25,6 & 59,4 & 10,7 & 28,3 & 61,0 \\
$20-21$ & Cinza amarelado & 17,4 & 28,9 & 53,6 & 10,9 & 22,5 & 66,6 \\
$23-24$ & Cinza amarelado & 12,3 & 23,5 & 64,2 & 7,2 & 15,8 & 77,0 \\
& & & & & & & \\
\end{tabular}

As curvas granulométricas das amostras de mesma profundidade, apresentadas na Figura 2, obtidas com e sem o uso de defloculante, não são coincidentes, principalmente na faixa correspondente às frações areia fina, silte e argila. Esse fato evidencia a agregação dessas partículas menores, formando flocos, que são dimensionados como uma fração maior quando o defloculante não está atuando. A Tabela 1 apresenta as porcentagens das diferentes granulometrias encontradas no perfil amostrado.

As amostras em todo o perfil são classificadas texturalmente como areias silto-argilosas, independente do uso ou não do defloculante. A porcentagem de areia aumenta com a profundidade, a partir de 12 metros, em contrapartida da diminuição da fração argila.

A passagem de coloração (vermelha a cinza e amarela) pode revelar ambientes diferenciados (oxidante a redutor) com o aumento de profundidade.

\section{Caracterização físico-química do solo e dos lixi- viados}

Os resultados das amostras de solo por FRX encontram-se nas Tabelas 2 e 3 . Há uma percentagem significativa de sílica no solo alcançando valores ao redor de $54 \%$, seguido de $\mathrm{Al}_{2} \mathrm{O}_{3}$, na média de $24 \%, \mathrm{Fe}_{2} \mathrm{O}_{3}$ em $15 \%, \mathrm{TiO}_{2}$ que apresentou média ao redor de $3 \%$. $\mathrm{P}_{2} \mathrm{O}_{5}, \mathrm{~K}_{2} \mathrm{O}, \mathrm{CaO}$ e $\mathrm{Na}_{2} \mathrm{O}$ apresentaram médias de 6,74\%,0,08\%,0,08\% e 0,06\% respectivamente. Em relação aos parâmetros Perda ao Fogo $\left(105^{\circ} \mathrm{C}\right.$ e $\left.1000^{\circ} \mathrm{C}\right)$ as amostras de solo apresentaram média de $6,74 \%$, com máximo valor de $9,52 \%$ e mínimo de $4,29 \%$.

Os elementos traços analisados apresentaram valores médios em $\mu \mathrm{g} / \mathrm{g}$ (em ordem crescente de concentração): Zircônio (563,96), Vanádio $(200,19)$, Bário $(76,05)$, Cromo $(46,81)$, Estrôncio $(42,16)$, Cobre $(35,91)$, Zinco $(35,08)$, Nióbio $(33,13)$, Gálio $(17,55)$, Chumbo $(13,92)$, Tório $(12,56)$, Níquel $(8,93)$, Ítrio $(7,75)$, Arsênio $(5,24)$, Estanho (4,97), Rubídio $(4,65)$, Molibdênio $(3,45)$. O enxofre apresentou uma concentração (estimada) média de $173,04 \mu \mathrm{g} / \mathrm{g}$.

Os teores de $\mathrm{SiO}_{2}$ e $\mathrm{K}_{2} \mathrm{O}$ apresentam-se em maiores porcentagens em amostras de maiores profundidades, enquanto que $\mathrm{TiO}_{2}, \mathrm{Al}_{2} \mathrm{O}_{3}, \mathrm{Fe}_{2} \mathrm{O}_{3}$, $\mathrm{MnO}$ e $\mathrm{CaO}$ são maiores em profundidades mais superficiais. As maiores concentrações de Zn, V, $\mathrm{Zr}$ e $\mathrm{Ga}$ são encontradas em profundidades mais rasas, diminuindo em profundidade. As concentrações de $\mathrm{Ba}, \mathrm{Sr}$ e $\mathrm{Pb}$ aumentam em profundidade. Os parâmetros Perda ao Fogo à $105^{\circ} \mathrm{C}$ e Perda ao Fogo à $1000^{\circ} \mathrm{C}$ apresentaram valores decrescente com a profundidade. Os demais elementos apresentam uma distribuição não relacionada com a profundidade. No entanto, todos apresentam concentrações significativas e podem estar relacionadas à disposição da vinhaça durante anos. 
Tabela 2 - Resultados da análise de solo pelo método de Fluorescência de Raios-X (óxidos e Perda ao Fogo - à $105^{\circ} \mathrm{C}$ e à $1000^{\circ} \mathrm{C}$ ).

Table 2 - Results of soils analysis by XRF methods (oxides and Loss on Ignition $-105^{\circ} \mathrm{C}$ and $1000^{\circ} \mathrm{C}$ ).

\begin{tabular}{|c|c|c|c|c|c|c|c|c|c|c|c|c|}
\hline $\begin{array}{c}\text { Intervalo de } \\
\text { Coleta }\end{array}$ & $\begin{array}{l}\mathrm{SiO}_{2} \\
(\%)\end{array}$ & $\begin{array}{c}\mathrm{TiO}_{2} \\
(\%)\end{array}$ & $\begin{array}{c}\mathrm{Al}_{2} \mathrm{O}_{3} \\
(\%)\end{array}$ & $\begin{array}{c}\mathrm{Fe}_{2} \mathrm{O}_{3} \\
(\%)\end{array}$ & $\begin{array}{c}\mathrm{MnO} \\
(\%)\end{array}$ & $\begin{array}{c}\mathrm{MgO} \\
(\%)\end{array}$ & $\begin{array}{l}\mathrm{CaO} \\
(\%)\end{array}$ & $\begin{array}{c}\mathrm{Na}_{2} \mathrm{O} \\
(\%)\end{array}$ & $\begin{array}{l}\mathrm{K}_{2} \mathrm{O} \\
(\%)\end{array}$ & $\begin{array}{c}\mathrm{P}_{2} \mathrm{O}_{5} \\
(\%)\end{array}$ & $\begin{array}{l}\text { \% Perda } \\
\left(105^{\circ} \mathrm{C}\right)\end{array}$ & $\begin{array}{l}\% \text { P.F. } \\
\left(1000^{\circ} \mathrm{C}\right)\end{array}$ \\
\hline 0 a $1 \mathrm{~m}$ & 45,00 & 3,83 & 27,40 & 14,30 & 0,06 & 0,05 & 0,10 & 0,06 & 0,02 & 0,19 & 1,09 & 7,74 \\
\hline 1 a $1,7 \mathrm{~m}$ & 44,30 & 3,66 & 27,70 & 13,90 & 0,06 & 0,05 & 0,14 & 0,06 & 0,02 & 0,21 & 0,96 & 8,65 \\
\hline 1,7 a $2 \mathrm{~m}$ & 40,60 & 3,84 & 29,30 & 15,00 & 0,06 & 0,04 & 0,15 & 0,06 & 0,03 & 0,20 & 1,00 & 9,52 \\
\hline 2 a $3 m$ & 46,00 & 3,57 & 27,30 & 13,30 & 0,06 & 0,05 & 0,15 & 0,06 & 0,03 & 0,24 & 0,93 & 8,17 \\
\hline 3 a $4 m$ & 48,50 & 3,51 & 25,60 & 13,10 & 0,06 & 0,05 & 0,11 & 0,06 & 0,03 & 0,15 & 1,06 & 7,60 \\
\hline 4 a $5 m$ & 51,20 & 3,42 & 24,60 & 11,70 & 0,06 & 0,06 & 0,13 & 0,06 & 0,03 & 0,13 & 1,08 & 7,33 \\
\hline 5 a $6 \mathrm{~m}$ & 52,10 & 3,36 & 24,40 & 11,00 & 0,05 & 0,07 & 0,12 & 0,06 & 0,03 & 0,13 & 1,05 & 7,48 \\
\hline 6 a $7 m$ & 50,40 & 3,37 & 24,90 & 12,20 & 0,06 & 0,07 & 0,09 & 0,06 & 0,06 & 0,14 & 0,94 & 7,57 \\
\hline 7 a $8 m$ & 51,40 & 3,22 & 24,60 & 12,10 & 0,06 & 0,06 & 0,10 & 0,05 & 0,06 & 0,22 & 0,78 & 7,15 \\
\hline 8 a $9 m$ & 49,60 & 3,34 & 25,30 & 13,00 & 0,06 & 0,05 & 0,09 & 0,06 & 0,08 & 0,15 & 0,81 & 7,34 \\
\hline 9 a $9,5 \mathrm{~m}$ & 48,60 & 3,42 & 25,70 & 13,60 & 0,06 & 0,05 & 0,08 & 0,06 & 0,08 & 0,14 & 0,78 & 7,28 \\
\hline 9,5 a $10 \mathrm{~m}$ & 49,30 & 3,23 & 24,50 & 14,10 & 0,06 & 0,05 & 0,07 & 0,05 & 0,08 & 0,16 & 1,02 & 7,27 \\
\hline 10 a $10,7 \mathrm{~m}$ & 48,00 & 3,43 & 26,00 & 13,40 & 0,06 & 0,05 & 0,09 & 0,06 & 0,08 & 0,17 & 0,84 & 7,67 \\
\hline 10,7 a $11 \mathrm{~m}$ & 52,80 & 3,10 & 23,80 & 12,10 & 0,06 & 0,05 & 0,06 & 0,06 & 0,10 & 0,13 & 0,85 & 6,85 \\
\hline 11 a $12 \mathrm{~m}$ & 51,60 & 3,12 & 24,50 & 12,30 & 0,06 & 0,05 & 0,06 & 0,06 & 0,10 & 0,14 & 0,91 & 6,95 \\
\hline 12 a $13 \mathrm{~m}$ & 53,60 & 2,88 & 23,90 & 11,40 & 0,06 & 0,05 & 0,06 & 0,06 & 0,11 & 0,14 & 0,75 & 6,98 \\
\hline 13 a $14 \mathrm{~m}$ & 57,40 & 2,62 & 22,10 & 10,20 & 0,05 & 0,06 & 0,07 & 0,06 & 0,10 & 0,15 & 0,69 & 6,38 \\
\hline 14 a $15 \mathrm{~m}$ & 53,80 & 2,88 & 24,00 & 11,40 & 0,04 & 0,05 & 0,06 & 0,06 & 0,11 & 0,16 & 0,72 & 6,67 \\
\hline 15 a $16 \mathrm{~m}$ & 61,80 & 2,27 & 20,70 & 8,10 & 0,04 & 0,06 & 0,05 & 0,05 & 0,10 & 0,15 & 0,74 & 5,80 \\
\hline 16 a $17 \mathrm{~m}$ & 60,00 & 2,40 & 21,80 & 8,70 & 0,04 & 0,06 & 0,06 & 0,06 & 0,11 & 0,16 & 0,71 & 5,82 \\
\hline 17 a $18 \mathrm{~m}$ & 62,30 & 2,22 & 20,80 & 8,00 & 0,04 & 0,06 & 0,05 & 0,06 & 0,11 & 0,16 & 0,65 & 5,41 \\
\hline 18 a $19 m$ & 63,00 & 2,22 & 20,50 & 7,80 & 0,04 & 0,06 & 0,05 & 0,06 & 0,10 & 0,15 & 0,71 & 5,26 \\
\hline 19 a $20 \mathrm{~m}$ & 58,70 & 2,52 & 23,00 & 9,00 & 0,04 & 0,06 & 0,05 & 0,06 & 0,12 & 0,18 & 0,61 & 5,54 \\
\hline 20 a $21 \mathrm{~m}$ & 59,40 & 2,43 & 22,70 & 9,00 & 0,04 & 0,06 & 0,05 & 0,06 & 0,12 & 0,18 & 0,48 & 5,42 \\
\hline 21 a $22 \mathrm{~m}$ & 61,30 & 2,29 & 22,20 & 8,00 & 0,04 & 0,06 & 0,09 & 0,06 & 0,12 & 0,18 & 0,44 & 5,19 \\
\hline 22 a $23 \mathrm{~m}$ & 66,50 & 2,01 & 19,70 & 6,10 & 0,03 & 0,07 & 0,06 & 0,06 & 0,12 & 0,15 & 0,58 & 4,67 \\
\hline 23 a $24 \mathrm{~m}$ & 70,10 & 1,73 & 17,80 & 5,20 & 0,03 & 0,07 & 0,09 & 0,06 & 0,12 & 0,14 & 0,42 & 4,29 \\
\hline
\end{tabular}


Tabela 3 - Resultados da análise de solo pelo método de Fluorescência de Raios-X (elementos traços).

Table 3 - Results of soils analysis by XRF methods (trace elements).

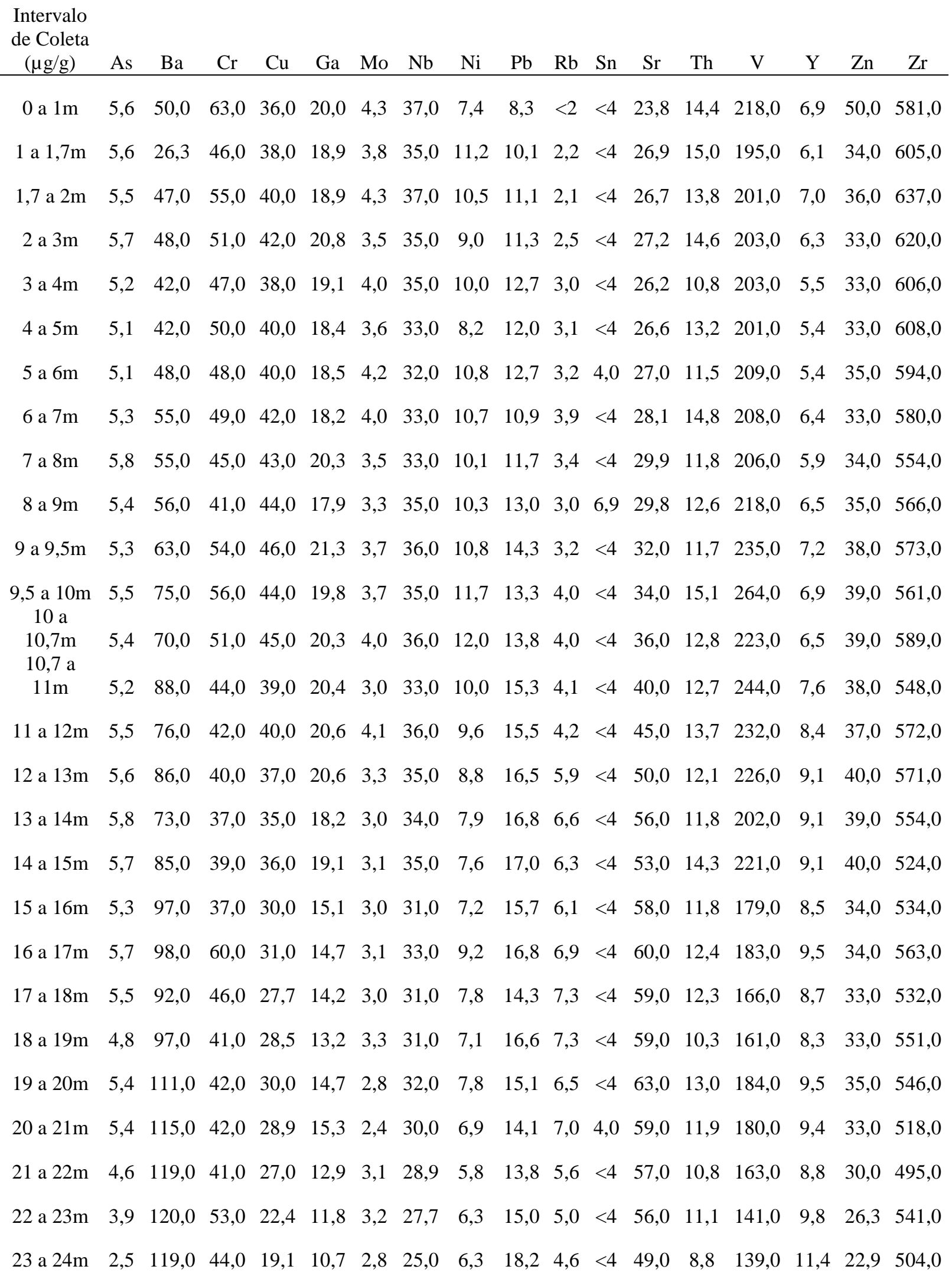


Tabela 4 - Resultados das análises químicas de lixiviados das amostras de solo ao longo do perfil de solo.

Table 4 - Results of chemical analysis of soil sample leachates along the soil profile.

\begin{tabular}{|c|c|c|c|c|c|c|c|c|c|c|}
\hline Intervalo de coleta & $\mathrm{pH}$ & $\begin{array}{l}\text { Eh } \\
\text { (V) }\end{array}$ & $\begin{array}{c}\text { C.E. } \\
(\mu \mathrm{S} / \mathrm{cm})\end{array}$ & $\begin{array}{c}\mathrm{Ca}^{2+} \\
(\mathrm{mg} / \mathrm{L})\end{array}$ & $\begin{array}{c}\mathrm{Mg}^{2+} \\
(\mathrm{mg} / \mathrm{L})\end{array}$ & $\begin{array}{c}\mathrm{Na}^{+} \\
(\mathrm{mg} / \mathrm{L})\end{array}$ & $\begin{array}{c}\mathrm{K}^{+} \\
(\mathrm{mg} / \mathrm{L})\end{array}$ & $\begin{array}{c}\mathrm{Li}^{+} \\
(\mathrm{mg} / \mathrm{L})\end{array}$ & $\begin{array}{c}\mathrm{Br}^{-} \\
(\mathrm{mg} / \mathrm{L})\end{array}$ & $\begin{array}{c}\mathrm{F}^{-} \\
(\mathrm{mg} / \mathrm{L})\end{array}$ \\
\hline $0-1 \mathrm{~m}$ & 5,55 & 0,28 & 13,21 & 0,66 & 0,11 & 0,26 & 0,82 & $<0,01$ & $<0,01$ & $<0,01$ \\
\hline $1-1,7 \mathrm{~m}$ & 5,42 & 0,28 & 11,2 & 0,46 & 0,07 & 0,31 & 0,49 & $<0,01$ & $<0,01$ & $<0,01$ \\
\hline $1,7-2 \mathrm{~m}$ & 4,85 & 0,32 & 25,51 & 1,63 & 0,25 & 0,38 & 0,63 & 0,01 & $<0,01$ & $<0,01$ \\
\hline 2 a $3 m$ & 5,04 & 0,3 & 29,1 & 2,41 & 0,34 & 0,27 & $<0,05$ & 0,01 & $<0,01$ & $<0,01$ \\
\hline 3 a $4 m$ & 5,18 & 0,3 & 22,53 & 1,56 & 0,22 & 0,37 & $<0,05$ & 0,01 & $<0,01$ & $<0,01$ \\
\hline 4 a $5 \mathrm{~m}$ & 6,02 & 0,25 & 22 & 1,65 & 0,23 & 0,42 & $<0,05$ & $<0,01$ & 0,05 & $<0,01$ \\
\hline 5 a $6 \mathrm{~m}$ & 6,17 & 0,24 & 22,25 & 1,01 & 0,43 & 0,62 & $<0,05$ & 0,01 & 0,1 & $<0,01$ \\
\hline 6 a $7 \mathrm{~m}$ & 6,77 & 0,21 & 20,43 & 0,2 & 0,08 & 0,84 & 2,68 & $<0,01$ & 0,07 & $<0,01$ \\
\hline 7 a $8 m$ & 7,04 & 0,19 & 36,72 & 0,15 & 0,04 & 0,65 & 3,52 & $<0,01$ & 0,05 & 0,01 \\
\hline 8 a $9 m$ & 7,32 & 0,18 & 28,53 & 0,13 & $<0,03$ & 0,02 & 3,37 & $<0,01$ & $<0,01$ & 0,02 \\
\hline 9 a $9,5 \mathrm{~m}$ & 6,72 & 0,21 & 24,64 & 0,17 & $<0,03$ & 0,05 & $<0,05$ & 0,01 & $<0,01$ & $<0,01$ \\
\hline $9,5-10 \mathrm{~m}$ & 7,31 & 0,18 & 25,3 & 0,11 & $<0,03$ & 0,03 & 3,32 & $<0,01$ & $<0,01$ & 0,02 \\
\hline $10-10,7 \mathrm{~m}$ & 6,68 & 0,2 & 32,47 & 0,14 & $<0,03$ & 0,03 & 3,61 & $<0,01$ & $<0,01$ & $<0,01$ \\
\hline $10,7-11 \mathrm{~m}$ & 7,52 & 0,17 & 27,33 & 0,14 & $<0,03$ & 0,06 & 2,09 & $<0,01$ & $<0,01$ & 0,02 \\
\hline 11 a $12 \mathrm{~m}$ & 7,26 & 0,19 & 22,45 & 0,13 & $<0,03$ & 0,04 & 3,09 & $<0,01$ & $<0,01$ & 0,03 \\
\hline 12 a $13 \mathrm{~m}$ & 7,25 & 0,18 & 23,85 & 0,13 & $<0,03$ & 0,04 & 3,36 & $<0,01$ & $<0,01$ & 0,03 \\
\hline $13-14 m$ & 7,33 & 0,18 & 23,59 & 0,14 & $<0,03$ & 0,03 & 3,21 & $<0,01$ & $<0,01$ & 0,03 \\
\hline $14-15 m$ & 7,21 & 0,18 & 22,61 & 0,14 & $<0,03$ & 0,09 & 3,33 & 0,01 & $<0,01$ & 0,02 \\
\hline $15-16 \mathrm{~m}$ & 7,49 & 0,17 & 21,63 & 0,16 & $<0,03$ & 0,04 & 3,39 & $<0,01$ & $<0,01$ & 0,02 \\
\hline $16-17 m$ & 7,21 & 0,19 & 18,96 & 0,11 & $<0,03$ & 0,04 & 3 & $<0,01$ & $<0,01$ & 0,03 \\
\hline $17-18 m$ & 7 & 0,2 & 18,55 & 0,11 & $<0,03$ & 0,08 & 3,16 & $<0,01$ & $<0,01$ & 0,03 \\
\hline $18-19 m$ & 6,83 & 0,2 & 17,45 & 0,11 & $<0,03$ & 0,04 & 2,95 & $<0,01$ & $<0,01$ & 0,03 \\
\hline $19-20 m$ & 6,62 & 0,16 & 20,76 & 0,15 & $<0,03$ & 0,02 & 2,98 & $<0,01$ & $<0,01$ & 0,03 \\
\hline $20-21 \mathrm{~m}$ & 6,81 & 0,16 & 19,33 & 0,12 & $<0,03$ & 0,03 & 3 & $<0,01$ & $<0,01$ & 0,03 \\
\hline $21-22 m$ & 7,4 & 0,18 & 18,39 & 0,22 & $<0,03$ & 0,05 & 3,22 & $<0,01$ & $<0,01$ & 0,08 \\
\hline $22-23 m$ & 7,17 & 0,19 & 12,86 & 0,19 & $<0,03$ & 0,03 & 2,3 & $<0,01$ & $<0,01$ & 0,05 \\
\hline $23-24 m$ & 7,25 & 0,17 & 11,5 & 0,29 & $<0,03$ & 0,03 & 2,42 & $<0,01$ & $<0,01$ & 0,06 \\
\hline
\end{tabular}


Tabela 5 - Resultados das análises químicas de lixiviados das amostras de solo ao longo do perfil de solo.

Table 5 - Results of chemical analysis of soil sample leachates along the soil profile.

\begin{tabular}{|c|c|c|c|c|c|c|c|c|c|c|}
\hline Intervalo de coleta & $\begin{array}{l}\mathrm{NO}_{2}^{-}-\mathrm{N} \\
(\mathrm{mg} / \mathrm{L})\end{array}$ & $\begin{array}{l}\mathrm{NO}_{3}{ }^{-}-\mathrm{N} \\
(\mathrm{mg} / \mathrm{L})\end{array}$ & $\begin{array}{l}\mathrm{PO}_{4}{ }^{3-}-\mathrm{P} \\
(\mathrm{mg} / \mathrm{L})\end{array}$ & $\begin{array}{l}\mathrm{SO}_{4}{ }^{2-} \\
(\mathrm{mg} / \mathrm{L})\end{array}$ & $\begin{array}{c}\mathrm{Cl}^{-} \\
(\mathrm{mg} / \mathrm{L})\end{array}$ & $\begin{array}{c}\mathrm{Al} \\
(\mathrm{mg} / \mathrm{L})\end{array}$ & $\begin{array}{c}\mathrm{Si} \\
(\mathrm{mg} / \mathrm{L})\end{array}$ & $\begin{array}{c}\mathrm{Fe} \\
(\mathrm{mg} / \mathrm{L})\end{array}$ & $\begin{array}{c}\mathrm{Mn} \\
(\mathrm{mg} / \mathrm{L})\end{array}$ & $\begin{array}{c}\mathrm{V} \\
(\mathrm{mg} / \mathrm{L})\end{array}$ \\
\hline $0-1 \mathrm{~m}$ & $<0,002$ & 0,06 & $<0,02$ & 2,3 & 0,67 & 65,7 & 14,8 & 38 & 0,6 & 0,8 \\
\hline $1-1,7 \mathrm{~m}$ & $<0,002$ & 0,04 & $<0,02$ & 2,1 & 0,68 & 52,8 & 9,6 & 566 & 1,5 & 1,9 \\
\hline $1,7-2 \mathrm{~m}$ & $<0,002$ & 0,04 & $<0,02$ & 9,9 & 0,67 & 54,8 & 10 & 720 & 1,9 & 2,3 \\
\hline 2 a $3 m$ & $<0,002$ & 0,04 & $<0,02$ & 11,4 & 0,63 & 44,2 & 11 & 457 & 1,1 & 1,8 \\
\hline 3 a $4 m$ & $<0,002$ & 0,04 & $<0,02$ & 8 & 0,66 & 44 & 11,9 & 317 & 0,6 & 1,6 \\
\hline 4 a $5 \mathrm{~m}$ & $<0,002$ & 0,05 & $<0,02$ & 7,6 & 0,7 & 29,9 & 9,9 & 195 & 0,6 & 1,2 \\
\hline 5 a $6 \mathrm{~m}$ & $<0,002$ & 0,06 & $<0,02$ & 7,7 & 0,8 & 30,3 & 13,4 & 192 & 1 & 1,2 \\
\hline 6 a $7 m$ & $<0,002$ & 0,09 & $<0,02$ & 5,3 & 0,88 & 30,2 & 13,7 & 584 & 1,4 & 2,3 \\
\hline 7 a $8 m$ & $<0,002$ & 0,08 & 0,045 & 9,6 & 0,92 & 29,9 & 14,8 & 291 & 1,1 & 1,8 \\
\hline 8 a $9 m$ & $<0,002$ & 0,01 & $<0,02$ & 4,5 & 0,63 & 26,5 & 14,8 & 564 & 1,6 & 2,2 \\
\hline 9 a $9,5 \mathrm{~m}$ & $<0,002$ & 0,01 & $<0,02$ & 4,3 & 0,7 & 28,3 & 16,1 & 335 & 0,9 & 2,3 \\
\hline $9,5-10 m$ & $<0,002$ & 0,01 & $<0,02$ & 3,2 & 0,7 & 39,4 & 24,4 & 376 & 1,5 & 3,1 \\
\hline $10-10,7 \mathrm{~m}$ & $<0,002$ & 0,01 & $<0,02$ & 7,9 & 0,71 & 28,9 & 15,8 & 388 & 1,4 & 2,1 \\
\hline $10,7-11 \mathrm{~m}$ & 0,028 & 0,02 & $<0,02$ & 1,3 & 0,92 & 28,3 & 18,7 & 254 & 0,9 & 2,4 \\
\hline 11 a $12 \mathrm{~m}$ & $<0,002$ & 0,01 & $<0,02$ & 2 & 0,52 & 22,6 & 15,5 & 244 & 1,1 & 2 \\
\hline 12 a $13 \mathrm{~m}$ & $<0,002$ & 0,01 & $<0,02$ & 1,3 & 0,65 & 19 & 15,2 & 255 & 1,2 & 1,8 \\
\hline $13-14 m$ & $<0,002$ & 0,01 & $<0,02$ & 1,4 & 0,53 & 14,8 & 12,2 & 253 & 0,9 & 1,6 \\
\hline $14-15 m$ & $<0,002$ & 0,01 & $<0,02$ & 1,8 & 0,55 & 13,3 & 11,8 & 235 & 0,8 & 1,3 \\
\hline $15-16 m$ & $<0,002$ & 0,01 & $<0,02$ & 1,4 & 0,88 & 11,9 & 11,4 & 122 & 0,4 & 1,2 \\
\hline $16-17 m$ & $<0,002$ & 0,01 & $<0,02$ & 1,2 & 0,54 & 13,1 & 12,2 & 147 & 0,5 & 1,2 \\
\hline $17-18 m$ & $<0,002$ & 0,01 & $<0,02$ & 1,2 & 0,8 & 10,5 & 11,2 & 87 & 0,4 & 1 \\
\hline $18-19 m$ & $<0,002$ & 0,01 & $<0,02$ & 1,5 & 0,74 & 10,9 & 12,5 & 37 & 0,1 & 0,8 \\
\hline $19-20 m$ & $<0,002$ & 0,01 & $<0,02$ & 1,3 & 0,99 & 9,8 & 11,8 & 22 & 0,1 & 0,8 \\
\hline $20-21 m$ & $<0,002$ & 0,01 & $<0,02$ & 1,9 & 0,74 & 9,8 & 10,6 & 46 & 0,1 & 0,8 \\
\hline $21-22 m$ & $<0,002$ & 0,01 & $<0,02$ & 1 & 0,59 & 12 & 10,2 & 155 & 0,5 & 0,9 \\
\hline $22-23 m$ & $<0,002$ & 0,01 & $<0,02$ & 0,04 & 0,44 & 8,2 & 8,4 & 83 & 0,5 & 0,5 \\
\hline $23-24 m$ & 0,018 & 0,01 & $<0,02$ & $<0,02$ & 0,43 & 8,2 & 7 & 87 & 0,6 & 0,5 \\
\hline
\end{tabular}

Os resultados das análises do lixiviado encontram-se nas Tabelas 4 e 5. Em suma, os lixiviados apresentam $\mathrm{pH}$ entre 4,85 a 7,52, tornando-se mais neutros com a profundidade. O Eh variou entre 0,16 a $0,30 \mathrm{~V}$, com decréscimo dos valores com a profundidade. A condutividade elétrica (C.E.) variou entre 11,20 a $32,47 \mu \mathrm{S} / \mathrm{cm}$, com auÁguas Subterrâneas (2012) 26(1): 113-130. mento de seus valores com a maior profundidade do perfil de solo.

A correlação dos valores de $\mathrm{pH}$ e Eh medidos dos lixiviados apresenta um comportamento linear descendente $(\mathrm{Eh}=-0,0547 \mathrm{pH}+0,575$, com $\mathrm{R}^{2}=0,9119$, Equação 2) a medida que aumenta a profundidade, ou seja, os lixiviados das amostras 
se tornam mais neutros e o Eh mais redutor. Os valores de $\mathrm{pH}$ variam de 4,85 a 7,32 e do Eh 0,18 a $0,32 \mathrm{~V}$ entre as profundidades de 0 a 10 metros; nas amostras mais profundas (11 a 24 metros) os lixiviados apresentam valores de $\mathrm{pH}$ entre 6,62 e 7,52 e Eh de 0,17 a 0,2V. As amostras situam-se nos ambientes de transição, entre os ambientes da água subterrânea e os de contato com a atmosfera, de acordo a classificação de águas naturais em diversas condições de pH e Eh (Mason 1971).

Os lixiviados das amostras de solo apresentam concentrações de cátions $\mathrm{Ca}^{2+}$ entre 0,11 a 2,41 mg/L, $\mathrm{Mg}^{2+}$ entre <0,03 a $0,44 \mathrm{mg} / \mathrm{L}, \mathrm{Na}^{+}$ entre 0,03 a $0,84 \mathrm{mg} / \mathrm{L}$ e $\mathrm{K}^{+}$entre $<0,05$ a 3,39 $\mathrm{mg} / \mathrm{L}$. Os íons cálcio, magnésio e sódio diminuem suas concentrações com a profundidade do perfil, no entanto, o potássio possui comportamento inverso. $\mathrm{O}$ cátion $\mathrm{Li}^{+}$aparece próximo ao limite de detecção do equipamento, com concentração de 0,01 nos seguintes intervalos de profundidades: 1,7 a $2 \mathrm{~m}, 2$ a $3 \mathrm{~m}, 3$ a $4 \mathrm{~m}, 5$ a $6 \mathrm{~m}, 9$ a $9,5 \mathrm{~m}$ e 14 a $15 \mathrm{~m}$.

A Figura 3a apresenta a distribuição dos íons cálcio, magnésio e sódio do lixiviado ao longo do perfil. Há grande liberação desses elementos do solo ao lixiviado nas primeiras porções do perfil do solo (até 7 metros para os dois primeiros íons e 8 metros para o sódio), reduzindo em concentração após essas profundidades. O potássio, ao contrário, é liberado ao lixiviado após 6 metros de profundidade (Figura 3b).

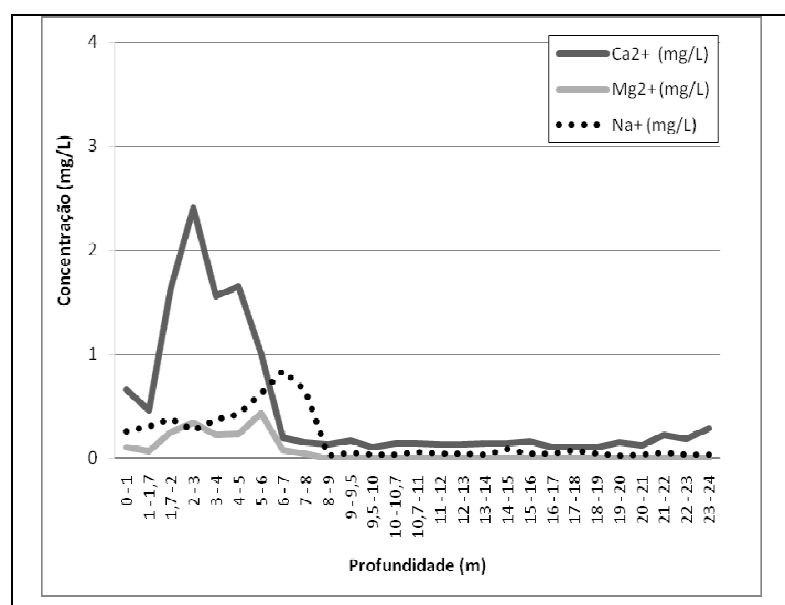

(a)

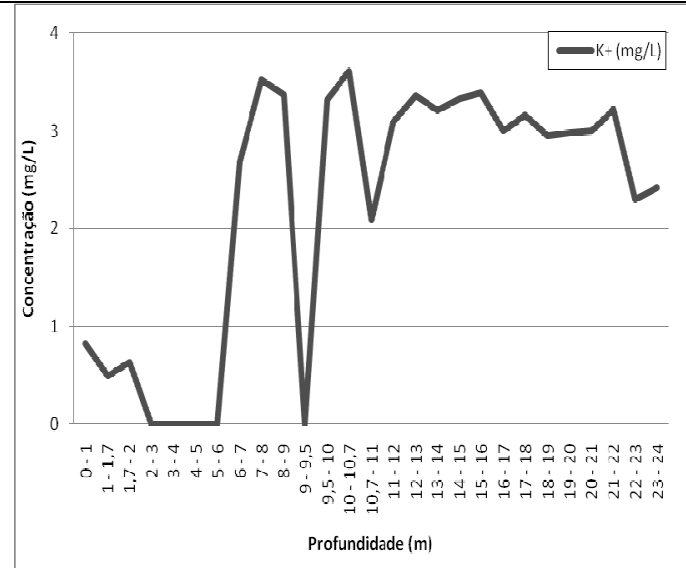

(b)

Figura 3 - Distribuição das concentrações dos íons cálcio, magnésio e sódio (a) e potássio (b), das amostras de lixiviado ao longo do perfil.

Figure 3 - Distribution of concentrations of calcium, magnesium and sodium (a) and potassium (b) of soil samples leachates along the profile.

Em relação aos ânions, os valores de $\mathrm{Br}^{-}$, $\mathrm{NO}_{2}{ }^{-}-\mathrm{N}$ e $\mathrm{PO}_{4}{ }^{3-}-\mathrm{P}$ apresentam valores próximos aos limites de detecção $(0,01 \mathrm{mg} / \mathrm{L}, 0,002 \mathrm{mg} / \mathrm{L}$ e 0,02 $\mathrm{mg} / \mathrm{L}$, respectivamente). As concentrações dos ânions $\mathrm{F}^{-}$variam de $<0,01$ a $0,08 \mathrm{mg} / \mathrm{L}, \mathrm{NO}_{3}^{-}{ }^{-} \mathrm{N}$ situa-se entre 0,01 a $0,09 \mathrm{mg} / \mathrm{L}, \mathrm{SO}_{4}{ }^{2-}$ entre $<0,02$ a $11,4 \mathrm{mg} / \mathrm{L} \mathrm{e} \mathrm{Cl}^{-}$entre 0,43 a $0,99 \mathrm{mg} / \mathrm{L}$. O fluoreto apresenta aumento de concentração com a profun- didade e o comportamento inverso é observado nos íons $\mathrm{NO}_{3}{ }^{-}-\mathrm{N}$ e $\mathrm{SO}_{4}{ }^{2-}$. O cloreto não possui comportamento diferenciado com a profundidade. As Figuras 4 (a) e 4 (b) apresentam a distribuição destes íons com a profundidade.

Os resultados da lixiviação por ácido nítrico são apresentados nas Tabelas 6 e 7. 


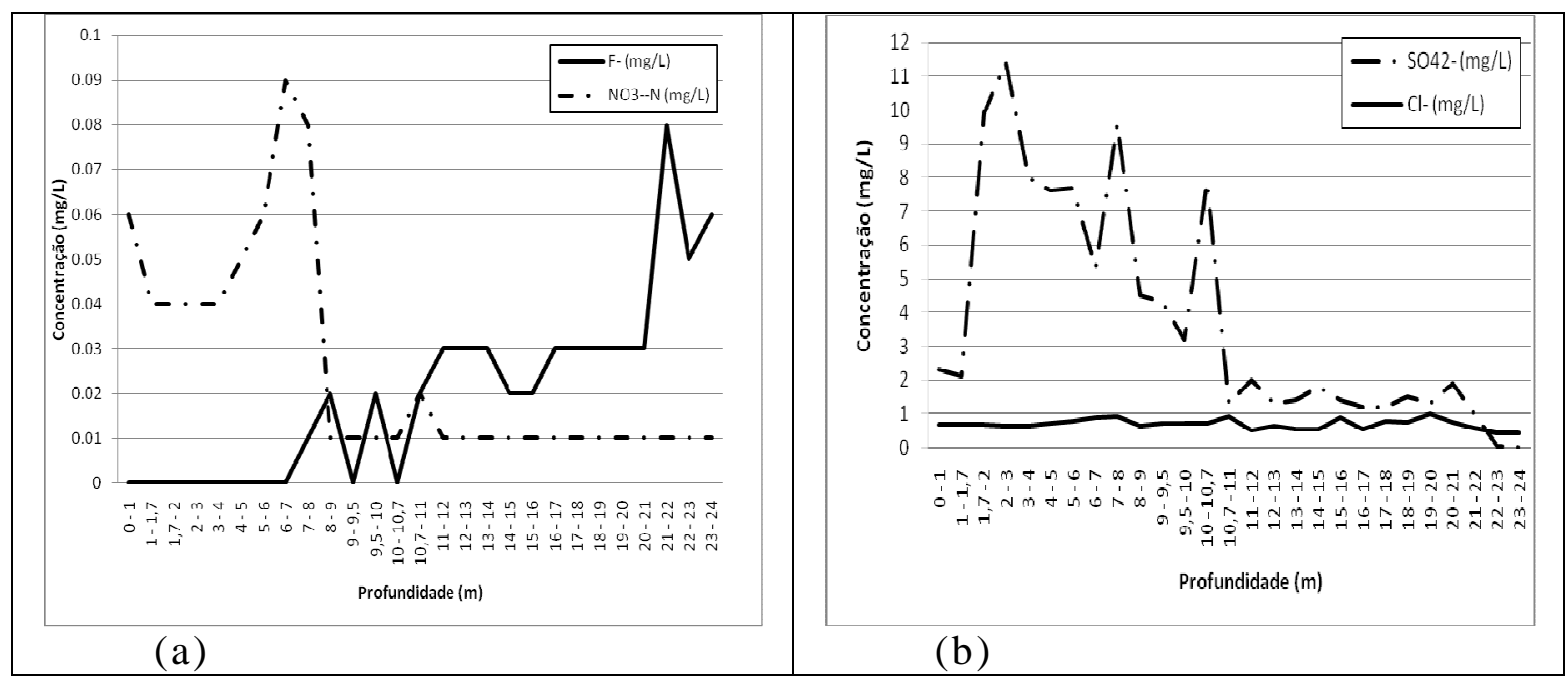

Figura 4 - Distribuição das concentrações de fluoreto e nitrato (a), sulfato e cloreto (b) e em lixiviados das amostras de solo por profundidade.

Figure 4 - Distribution of concentrations of Fluoride and Nitrate (a), sulfate and chloride (b) of soil samples leachates along the profile.

Tabela 6 - Resultados das análises químicas de lixiviados por ácido nítrico das amostras de solo ao longo do perfil de solo. Table 6 - Results of chemical analysis of leachates by nitric acid method from soil samples along the profile. (continua) Intervalo

de Coleta

\begin{tabular}{cccccccccccccccc} 
( $\mu \mathrm{g} / \mathrm{L})$ & $\mathrm{Li}$ & $\mathrm{Be}$ & $\mathrm{Sc}$ & $\mathrm{Ti}$ & $\mathrm{Cr}$ & $\mathrm{Co}$ & $\mathrm{Ni}$ & $\mathrm{Cu}$ & $\mathrm{Zn}$ & $\mathrm{Ga}$ & $\mathrm{Ge}$ & $\mathrm{As}$ & $\mathrm{Se}$ & $\mathrm{Rb}$ & $\mathrm{Y}$ \\
\hline 0 a 1m & 0,6 & 0,6 & 129,0 & 120,0 & 63,0 & 7,6 & 7,3 & 120,0 & 888,0 & 27,0 & 0,6 & 2,3 & 2,8 & 10,6 & 25,6 \\
1 a 1,7m & 0,3 & 0,6 & 115,0 & 424,0 & 143,0 & 6,9 & 8,4 & 143,0 & 139,0 & 54,0 & 0,5 & 3,8 & 1,0 & 17,5 & 6,7 \\
1,7 a 2m & 0,3 & 0,6 & 126,0 & 503,0 & 159,0 & 8,0 & 10,6 & 184,0 & 176,0 & 62,0 & 0,5 & 5,5 & 1,0 & 17,7 & 6,9 \\
2 a 3m & 0,3 & 0,6 & 114,0 & 414,0 & 105,0 & 6,0 & 9,0 & 267,0 & 128,0 & 63,0 & 0,6 & 5,8 & 1,0 & 24,9 & 6,1 \\
3 a 4m & 0,3 & 0,4 & 134,0 & 359,0 & 70,0 & 5,2 & 8,7 & 177,0 & 148,0 & 69,0 & 0,4 & 2,8 & 1,1 & 20,8 & 5,2 \\
4 a 5m & 0,3 & 0,3 & 123,0 & 172,0 & 51,0 & 5,4 & 6,5 & 140,0 & 90,0 & 45,0 & 0,3 & 3,0 & 1,1 & 29,0 & 5,2 \\
5 a 6m & 0,3 & 0,5 & 125,0 & 319,0 & 90,0 & 9,0 & 10,8 & 131,0 & 104,0 & 41,0 & 0,6 & 5,4 & 2,2 & 42,2 & 13,4 \\
6 a 7m & 0,6 & 0,6 & 129,0 & 120,0 & 63,0 & 7,6 & 7,3 & 120,0 & 888,0 & 27,0 & 0,6 & 2,3 & 2,8 & 10,6 & 25,6 \\
7 a 8m & 0,3 & 0,4 & 100,0 & 560,0 & 84,0 & 5,3 & 11,6 & 274,0 & 113,0 & 92,0 & 0,5 & 7,1 & 1,1 & 51,7 & 4,7 \\
8 a 9m & 0,2 & 0,4 & 145,0 & 677,0 & 75,0 & 5,8 & 10,6 & 177,0 & 122,0 & 68,0 & 0,5 & 4,1 & 1,2 & 59,9 & 4,5 \\
9 a 9,5m & 0,3 & 0,4 & 151,0 & 559,0 & 57,0 & 4,5 & 8,4 & 156,0 & 126,0 & 57,0 & 0,6 & 3,0 & 1,4 & 52,9 & 5,6 \\
9,5 a 10m & 0,4 & 0,7 & 262,0 & 704,0 & 72,0 & 6,0 & 9,9 & 225,0 & 167,0 & 55,0 & 1,0 & 5,3 & 2,5 & 61,2 & 14,3 \\
10 a 10,7m & 0,3 & 0,4 & 155,0 & 485,0 & 69,0 & 6,3 & 10,4 & 190,0 & 140,0 & 58,0 & 0,7 & 5,0 & 1,6 & 52,5 & 9,5 \\
10,7 a 11m & 0,2 & 0,4 & 196,0 & 428,0 & 50,0 & 5,3 & 8,2 & 149,0 & 91,0 & 36,0 & 0,8 & 3,5 & 1,8 & 50,2 & 16,7
\end{tabular}


Tabela 6 - Resultados das análises químicas de lixiviados por ácido nítrico das amostras de solo ao longo do perfil de solo. Table 6 - Results of chemical analysis of leachates by nitric acid method from soil samples along the profile. (conclusão) Intervalo

de Coleta

\begin{tabular}{|c|c|c|c|c|c|c|c|c|c|c|c|c|c|c|c|}
\hline$(\mu \mathrm{g} / \mathrm{L})$ & $\mathrm{Li}$ & $\mathrm{Be}$ & $\mathrm{Sc}$ & $\mathrm{Ti}$ & $\mathrm{Cr}$ & $\mathrm{Co}$ & $\mathrm{Ni}$ & $\mathrm{Cu}$ & $\mathrm{Zn}$ & $\mathrm{Ga}$ & $\mathrm{Ge}$ & As & $\mathrm{Se}$ & $\mathrm{Rb}$ & $\mathrm{Y}$ \\
\hline 11 a $12 \mathrm{~m}$ & 0,2 & 0,4 & 175,0 & 366,0 & 43,0 & 4,2 & 6,2 & 140,0 & 91,0 & 31,0 & 0,8 & 3,5 & 1,9 & 40,9 & 18,6 \\
\hline 12 a $13 \mathrm{~m}$ & 0,1 & 0,4 & 165,0 & 349,0 & 41,0 & 4,2 & 6,3 & 137,0 & 85,0 & 19,0 & 1,3 & 5,7 & 3,2 & 40,0 & 20,7 \\
\hline 13 a $14 \mathrm{~m}$ & 0,1 & 0,4 & 144,0 & 333,0 & 31,0 & 3,1 & 4,3 & 102,0 & 85,0 & 14,0 & 0,8 & 3,0 & 1,7 & 37,4 & 7,9 \\
\hline 14 a $15 \mathrm{~m}$ & 0,1 & 0,4 & 122,0 & 241,0 & 24,0 & 2,7 & 4,1 & 113,0 & 68,0 & 9,0 & 0,6 & 3,2 & 1,4 & 34,5 & 6,2 \\
\hline 15 a $16 \mathrm{~m}$ & 0,1 & 0,3 & 107,0 & 179,0 & 21,0 & 1,6 & 3,1 & 113,0 & 59,0 & 7,0 & 0,5 & 2,7 & 1,1 & 31,5 & 5,7 \\
\hline 16 a $17 \mathrm{~m}$ & 0,1 & 0,5 & 113,0 & 219,0 & 26,0 & 1,7 & 3,1 & 124,0 & 65,0 & 8,0 & 0,4 & 2,4 & 0,9 & 34,2 & 4,6 \\
\hline 17 a $18 \mathrm{~m}$ & 0,1 & 0,4 & 94,0 & 135,0 & 14,0 & 1,3 & 2,1 & 87,0 & 55,0 & 5,0 & 0,5 & 2,6 & 0,9 & 33,9 & 4,6 \\
\hline 18 a $19 m$ & 0,1 & 0,3 & 121,0 & 123,0 & 10,0 & 1,0 & 1,7 & 86,0 & 56,0 & 4,0 & 0,6 & 3,8 & 1,4 & 34,9 & 5,8 \\
\hline 19 a $20 \mathrm{~m}$ & 0,1 & 0,4 & 158,0 & 107,0 & 14,0 & 0,8 & 1,6 & 124,0 & 48,0 & 3,0 & 0,7 & 3,9 & 1,7 & 34,6 & 8,3 \\
\hline 20 a $21 \mathrm{~m}$ & 0,1 & 0,4 & 177,0 & 137,0 & 13,0 & 1,0 & 1,9 & 109,0 & 60,0 & 4,0 & 0,9 & 4,5 & 2,4 & 33,9 & 14,6 \\
\hline 21 a $22 \mathrm{~m}$ & 0,1 & 0,4 & 141,0 & 199,0 & 20,0 & 1,7 & 2,6 & 125,0 & 61,0 & 6,0 & 1,0 & 5,4 & 2,8 & 33,2 & 29,3 \\
\hline 22 a $23 \mathrm{~m}$ & 0,1 & 0,3 & 95,0 & 115,0 & 11,0 & 2,2 & 1,4 & 104,0 & 48,0 & 2,0 & 0,9 & 4,4 & 3,0 & 28,2 & 34,3 \\
\hline 23 a $24 m$ & 0,1 & 0,4 & 98,0 & 125,0 & 21,0 & 3,1 & 1,8 & 102,0 & 47,0 & 4,0 & 1,9 & 8,2 & 6,2 & 17,8 & 77,8 \\
\hline
\end{tabular}

Ferro (Fe), Silício ( $\mathrm{Si})$, Alumínio (Al), Manganês (Mn) e Vanádio (V) foram os elementos encontrados em maiores concentrações nas amostras dos lixiviados, condizente com as elevadas concentrações encontradas nas amostras de solo. As concentrações no lixiviado variaram de 11 a $720 \mathrm{mg} / \mathrm{L}, 7$ a $24 \mathrm{mg} / \mathrm{L}, 8,2$ a $65,7 \mathrm{mg} / \mathrm{L}, 0,1$ a 1,9 $\mathrm{mg} / \mathrm{L}$ e 0,48 a $3,09 \mathrm{mg} / \mathrm{L}$ respectivamente. O Ferro foi liberado para o lixiviado em profundidades mais rasas (entre 1 a 4 metros) e ao longo do perfil até 15 metros. Mesmo assim um valor elevado de concentração de Ferro permanece entre 22 a 155 $\mathrm{mg} / \mathrm{L}$ no lixiviado em maiores profundidades. As concentrações de Manganês apresentam um mesmo comportamento que o Ferro, porém em valores de concentrações bem menores. As concentrações de alumínio também decrescem com a profundidade, com ajuste de curva polinomial de segundo grau (Equação $3-\mathrm{Al}=0,0674$ prof $^{2}-3,7359+$ 60,833 , com $\mathrm{R}^{2}$ de 0,906 ). O elemento Vanádio também possui uma distribuição de concentrações decrescente ao longo do perfil. Já o silício apresenta valores maiores no intervalo entre 6 e 13 metros. Os elementos Cério (Ce), Titânio (Ti), Zinco (Zn), Bário (Ba), Cobre $(\mathrm{Cu})$, Escândio $(\mathrm{Sc})$, Chumbo $(\mathrm{Pb})$, Lantânio (La) e Cromo (Cr) apresentam concentrações significativas, porém, em valores bem inferiores aos citados anteriormente.
Para melhor visualização e análise, os elementos foram agrupados em função de valores de concentração, similaridade, comportamento em relação à profundidade do perfil do solo, mudanças de textura e/ ou ambiente redox (discriminado pelas variações de $\mathrm{pH}$ e Eh e pela coloração do material do solo).

Os elementos Cromo (Cr), Zinco (Zn), Chumbo $(\mathrm{Pb})$, Cério $(\mathrm{Ce})$, Níquel $(\mathrm{Ni})$, Cobre $(\mathrm{Cu})$, Lítio (Li), Estanho (Sn), Titânio (Ti), Escândio $(\mathrm{Sc})$, Cobalto (Co), Gálio (Ga), Estrôncio ( $\mathrm{Sr}$ ) e Bismuto (Bi) também apresentam distribuição de concentrações de acordo com a profundidade. Os referidos elementos apresentam-se em baixas concentrações (micrograma por litro $-\mu \mathrm{g} / \mathrm{L}$ ), e a distribuição das concentrações é decrescente em relação ao perfil de solo. Os valores de concentração desses elementos apresentam as seguintes variações: cromo - entre 10 e $159 \mu \mathrm{g} / \mathrm{L}$, zinco - entre 47 e $888 \mu \mathrm{g} / \mathrm{L}$, chumbo - 7 e $143 \mu \mathrm{g} / \mathrm{L}$, cério - 268 e $1247 \mu \mathrm{g} / \mathrm{L}$, níquel - 1,4 e 11,6 $\mu \mathrm{g} / \mathrm{L}$, cobre - 86 e $274 \mu \mathrm{g} / \mathrm{L}$, lítio - 0,06 e 0,56 $\mu \mathrm{g} / \mathrm{L}$, estanho - 0,16 e $0,50 \mu \mathrm{g} / \mathrm{L}$, titânio - entre 107 e $904 \mu \mathrm{g} / \mathrm{L}$, escândio - entre 94 e $262 \mu \mathrm{g} / \mathrm{L}$, cobalto - 0,8 e 9,0 $\mu \mathrm{g} / \mathrm{L}$, gálio - 2 e $92 \mu \mathrm{g} / \mathrm{L}$, estrôncio - entre 5,8 e $50,1 \mu \mathrm{g} / \mathrm{L}$ e bismuto - entre 0,02 e $0,09 \mu \mathrm{g} / \mathrm{L}$. 
Os demais elementos da Tabela 4 do lixiviado apresentam baixas concentrações (em migrograma por litro $-\mu \mathrm{g} / \mathrm{L}$ ) e não possuem comportamentos diferenciados em função da profundidade do solo.

$\mathrm{O}$ arsênio (As) ocorre ao longo de todo o perfil e varia entre 2,3 a $8,3 \mu \mathrm{g} / \mathrm{L}$, não possuindo comportamento direto com a profundidade ou textura do solo. O mesmo ocorre com os elementos césio $(\mathrm{Cs})$, urânio $(\mathrm{U})$, tório $(\mathrm{Th})$ e cádmio $(\mathrm{Cd})$, cujas concentrações variam ao longo do perfil de solo de 268 a $1247 \mu \mathrm{g} / \mathrm{L}, 15,0$ a $62,6 \mu \mathrm{g} / \mathrm{L}, 24,1$ a $63,1 \mu \mathrm{g} / \mathrm{L}$, e 0,03 a $0,09 \mu \mathrm{g} / \mathrm{L}$, respectivamente.

Dentro deste grupo de elementos que não possuem relação direta com a textura do solo, os elementos selênio (Se), lantânio (La), praseodímio $(\mathrm{Pr})$, ítrio (Y) e germânio (Ge) possuem comportamentos similares ao longo do perfil de solo, e apresentam as seguintes variações respectivas: 0,9 a $6,2 \mu \mathrm{g} / \mathrm{L}, 12$ a $294 \mu \mathrm{g} / \mathrm{L}, 5,2$ a $84,8 \mu \mathrm{g} / \mathrm{L}, 4,5$ a $77,8 \mu \mathrm{g} / \mathrm{L}$, e 0,3 a $1,9 \mu \mathrm{g} / \mathrm{L}$.

Tabela 7 - Resultados das análises químicas de lixiviados por ácido nítrico das amostras de solo ao longo do perfil de solo. Table 7 - Results of chemical analysis of leachates by nitric acid method from soil samples along the profile.

\begin{tabular}{|c|c|c|c|c|c|c|c|c|c|c|c|c|c|c|}
\hline $\begin{array}{c}\text { Intervalo de } \\
\text { Coleta }(\mu \mathrm{g} / \mathrm{L})\end{array}$ & Mo & $\mathrm{Cd}$ & $\mathrm{Sn}$ & $\mathrm{Sb}$ & $\mathrm{Te}$ & Cs & $\mathrm{Ba}$ & $\mathrm{Tl}$ & $\mathrm{Pb}$ & $\mathrm{Bi}$ & $\mathrm{Th}$ & $\mathrm{U}$ & $\mathrm{La}$ & $\mathrm{Ce}$ \\
\hline 0 a $1 \mathrm{~m}$ & 0,09 & 0,09 & 0,16 & $<0,01$ & $<0,01$ & 0,27 & 38,0 & 0,2 & 90,0 & 0,0 & 24,1 & 18,6 & 83,0 & 1125,0 \\
\hline 1 a $1,7 \mathrm{~m}$ & 0,08 & 0,05 & 0,43 & $<0,01$ & 0,06 & 0,55 & 61,0 & 0,2 & 121,0 & 0,1 & 47,7 & 19,5 & 18,0 & 541,0 \\
\hline 1,7 a $2 \mathrm{~m}$ & 0,10 & 0,06 & 0,39 & 0,03 & 0,06 & 0,57 & 65,0 & 0,2 & 141,0 & 0,1 & 49,5 & 21,5 & 19,0 & 570,0 \\
\hline 2 a $3 \mathrm{~m}$ & $<0,01$ & 0,06 & 0,50 & 0,03 & $<0,01$ & 0,50 & 69,0 & 0,4 & 131,0 & 0,1 & 34,5 & 20,5 & 15,0 & 830,0 \\
\hline 3 a $4 m$ & $<0,01$ & 0,05 & 0,34 & $<0,01$ & 0,04 & 0,49 & 52,0 & 0,2 & 118,0 & 0,1 & 56,9 & 18,8 & 16,0 & 1174,0 \\
\hline 4 a $5 \mathrm{~m}$ & $<0,01$ & 0,03 & 0,21 & 0,04 & $<0,01$ & 0,40 & 56,0 & 0,2 & 94,0 & 0,0 & 38,6 & 23,9 & 19,0 & 1010,0 \\
\hline 5 a $6 \mathrm{~m}$ & 0,07 & 0,05 & 0,23 & $<0,01$ & 0,03 & 1,14 & 83,0 & 0,3 & 90,0 & 0,0 & 42,3 & 28,2 & 72,0 & 1219,0 \\
\hline 6 a $7 m$ & $<0,01$ & 0,05 & 0,35 & 0,03 & 0,08 & 0,94 & 38,0 & 0,2 & 90,0 & 0,0 & 24,1 & 18,6 & 83,0 & 1125,0 \\
\hline 7 a $8 m$ & $<0,01$ & 0,04 & 0,44 & 0,08 & $<0,01$ & 0,94 & 116,0 & 0,2 & 111,0 & 0,1 & 30,6 & 15,2 & 12,0 & 1078,0 \\
\hline 8 a $9 m$ & $<0,01$ & 0,04 & 0,50 & $<0,01$ & $<0,01$ & 1,02 & 132,0 & 0,2 & 129,0 & 0,1 & 55,3 & 18,4 & 15,0 & 1232,0 \\
\hline 9 a $9,5 \mathrm{~m}$ & $<0,01$ & 0,04 & 0,41 & $<0,01$ & $<0,01$ & 1,05 & 149,0 & 0,6 & 111,0 & 0,1 & 49,8 & 33,8 & 30,0 & 1126,0 \\
\hline 9,5 a $10 \mathrm{~m}$ & $<0,01$ & 0,08 & 0,26 & $<0,01$ & 0,03 & 1,04 & 518,0 & 1,0 & 143,0 & 0,1 & 59,3 & 62,6 & 70,0 & 1247,0 \\
\hline 10 a $10,7 \mathrm{~m}$ & $<0,01$ & 0,04 & 0,29 & 0,04 & 0,04 & 0,94 & 291,0 & 1,0 & 127,0 & 0,0 & 42,8 & 28,6 & 38,0 & 1103,0 \\
\hline 10,7 a $11 \mathrm{~m}$ & $<0,01$ & 0,05 & 0,19 & 0,03 & $<0,01$ & 0,79 & 274,0 & 1,4 & 97,0 & 0,0 & 46,2 & 32,2 & 56,0 & 793,0 \\
\hline 11 a $12 \mathrm{~m}$ & $<0,01$ & 0,03 & 0,19 & $<0,01$ & $<0,01$ & 0,74 & 114,0 & 0,7 & 101,0 & 0,1 & 46,8 & 32,7 & 50,0 & 787,0 \\
\hline 12 a $13 \mathrm{~m}$ & $<0,01$ & 0,03 & 0,20 & $<0,01$ & 0,03 & 0,84 & 88,0 & 0,3 & 85,0 & 0,1 & 49,8 & 37,1 & 131,0 & 837,0 \\
\hline 13 a $14 \mathrm{~m}$ & $<0,01$ & $<0,01$ & 0,17 & $<0,01$ & $<0,01$ & 0,73 & 64,0 & 0,2 & 75,0 & 0,1 & 43,2 & 46,5 & 71,0 & 513,0 \\
\hline 14 a $15 \mathrm{~m}$ & $<0,01$ & $<0,01$ & 0,16 & $<0,01$ & $<0,01$ & 0,76 & 74,0 & 0,2 & 64,0 & 0,1 & 37,2 & 39,3 & 47,0 & 446,0 \\
\hline 15 a $16 \mathrm{~m}$ & $<0,01$ & $<0,01$ & $<0,01$ & $<0,01$ & $<0,01$ & 0,77 & 62,0 & 0,1 & 54,0 & 0,0 & 33,6 & 27,0 & 45,0 & 349,0 \\
\hline 16 a $17 \mathrm{~m}$ & $<0,01$ & $<0,01$ & $<0,01$ & $<0,01$ & $<0,01$ & 0,64 & 54,0 & 0,2 & 59,0 & 0,1 & 36,2 & 17,1 & 35,0 & 280,0 \\
\hline 17 a $18 \mathrm{~m}$ & $<0,01$ & $<0,01$ & $<0,01$ & $<0,01$ & $<0,01$ & 0,65 & 37,0 & 0,1 & 43,0 & 0,0 & 29,5 & 21,1 & 35,0 & 268,0 \\
\hline 18 a $19 m$ & $<0,01$ & $<0,01$ & $<0,01$ & 0,02 & 0,03 & 0,28 & 30,0 & 0,1 & 41,0 & 0,0 & 33,6 & 18,0 & 47,0 & 295,0 \\
\hline 19 a $20 \mathrm{~m}$ & $<0,01$ & $<0,01$ & $<0,01$ & $<0,01$ & $<0,01$ & 0,61 & 26,0 & 0,2 & 37,0 & 0,0 & 32,0 & 30,9 & 55,0 & 293,0 \\
\hline 20 a $21 \mathrm{~m}$ & $<0,01$ & $<0,01$ & $<0,01$ & $<0,01$ & $<0,01$ & 0,36 & 28,0 & 0,2 & 27,0 & 0,0 & 35,6 & 54,8 & 65,0 & 299,0 \\
\hline 21 a $22 \mathrm{~m}$ & $<0,01$ & $<0,01$ & $<0,01$ & 0,04 & $<0,01$ & 0,42 & 32,0 & 0,1 & 21,0 & 0,0 & 37,3 & 33,4 & 71,0 & 299,0 \\
\hline 22 a $23 \mathrm{~m}$ & $<0,01$ & $<0,01$ & $<0,01$ & $<0,01$ & $<0,01$ & 0,30 & 49,0 & 1,3 & 14,0 & 0,0 & 38,4 & 18,9 & 74,0 & 662,0 \\
\hline 23 a $24 \mathrm{~m}$ & $<0,01$ & $<0,01$ & $<0,01$ & $<0,01$ & $<0,01$ & 0,15 & 68,0 & 0,3 & 7,0 & 0,0 & 42,3 & 16,8 & 294,0 & 479,0 \\
\hline
\end{tabular}


Na Tabela 8 os resultados da análise estatística de correlação matricial são apresentados sintetizados, e o pH e fluoreto mostram correlação positiva com a profundidade. Os elementos sulfato, litio, gálio, fluoreto, cromo, cobalto, níquel, estrôncio, estanho, chumbo e alumínio, e o parâmetro Eh apresentaram correlação negativa. Consideraram-se uma boa correlação, resultados com valores de $\mathrm{r}>0,70$.

As maiores correlações se observam para os elementos fluoreto, cromo, cobalto, níquel, estrôncio, estanho, chumbo e alumínio. A matriz mostra correlações altas e positivas de níquel e chumbo, gálio e estanho, selênio e ítrio, estanho e chumbo, e ferro e manganês. As correlações negativas elevadas $\left(\mathrm{R}^{2}>0,90\right)$ restringem-se ao $\mathrm{pH}$ com Eh, ao $\mathrm{pH}$ com cálcio e à profundidade com alumínio, e as positivas entre niquel e chumbo, gálio e estanho, selênio e ítrio, chumbo e estanho, e ferro e manganês.

Tabela 8 - Resultados da análise estatística de correlação matricial (Pearson - r) entre os elementos químicos, pH, Eh, C.E. e profundidade.

Table 8 - Results of statistical analysis of matrix correlation (Pearson - r) among chemical elements, pH, Eh, E.C. of leachates and depth.

\begin{tabular}{|c|c|c|c|c|c|c|c|c|}
\hline \multirow{2}{*}{$\begin{array}{c}\text { Correlação } \\
\text { (Pearson - r) } \\
\text { p< } 0,05\end{array}$} & \multicolumn{2}{|c|}{$0,70-0,75$} & \multicolumn{2}{|c|}{ 0,75-0,80 } & \multicolumn{2}{|c|}{ 0,80-0,90 } & \multicolumn{2}{|c|}{$0,90-1,00$} \\
\hline & $\begin{array}{c}\text { Correlação } \\
\text { positiva }\end{array}$ & $\begin{array}{c}\text { Correlação } \\
\text { negativa }\end{array}$ & $\begin{array}{c}\text { Correlação } \\
\text { positiva }\end{array}$ & $\begin{array}{c}\text { Correla- } \\
\text { ção } \\
\text { negativa }\end{array}$ & $\begin{array}{c}\text { Correlação } \\
\text { positiva }\end{array}$ & $\begin{array}{c}\text { Correlação } \\
\text { negativa }\end{array}$ & $\begin{array}{c}\text { Correlação } \\
\text { positiva }\end{array}$ & $\begin{array}{c}\text { Correlação } \\
\text { negativa }\end{array}$ \\
\hline Prof. (m) & $\mathrm{pH}$ & $\mathrm{SO} 4$ & - & $\begin{array}{c}\text { Eh, Li, } \\
\text { Ga }\end{array}$ & $\mathrm{F}$ & $\begin{array}{l}\mathrm{Cr}, \mathrm{Co}, \mathrm{Ni} \\
\mathrm{Sr}, \mathrm{Sn}, \mathrm{Pb} \\
\end{array}$ & - & $\mathrm{Al}$ \\
\hline $\mathrm{pH}$ & - & $\mathrm{Cr}$ & K & $\begin{array}{l}\mathrm{Mg}, \mathrm{Sr}, \\
\mathrm{Al}\end{array}$ & - & $\mathrm{Ca}$ & - & Eh \\
\hline Eh $(\mathrm{V})$ & - & - & $\mathrm{Mg}, \mathrm{Cr}$ & - & $\mathrm{Ca}, \mathrm{Sr}, \mathrm{Al}$ & $\mathrm{K}$, & - & - \\
\hline C.E. (uS/cm) & $\mathrm{Cu}$ & & & & & & & \\
\hline $\mathrm{Ca}(\mathrm{mg} / \mathrm{L})$ & $\mathrm{SO}_{4}{ }^{2-}$ & - & - & $\mathrm{K}$ & $\mathrm{Mg}$ & - & - & - \\
\hline $\mathrm{Mg}(\mathrm{mg} / \mathrm{L})$ & $\mathrm{SO}_{4}{ }^{2-}$ & - & - & $\mathrm{K}$, & - & - & - & - \\
\hline $\mathrm{Na}(\mathrm{mg} / \mathrm{L})$ & $\mathrm{Sr}$ & - & - & - & $\mathrm{Br}$ & - & NO3 & - \\
\hline $\mathrm{Br}(\mathrm{mg} / \mathrm{L})$ & $\mathrm{NO} 3$ & & & & & & & \\
\hline $\mathrm{F}(\mathrm{mg} / \mathrm{L})$ & $\operatorname{Pr}$ & $\mathrm{Co}, \mathrm{Ni}, \mathrm{Al}$ & - & $\mathrm{Pb}$ & - & - & - & - \\
\hline $\mathrm{NO}^{-}-\mathrm{N}(\mathrm{mg} / \mathrm{L})$ & - & - & $\mathrm{Li}, \mathrm{Sr}$ & - & - & - & - & - \\
\hline $\mathrm{SO}_{4}^{2-5}(\mathrm{mg} / \mathrm{L})$ & $\begin{array}{c}\mathrm{Cr}, \mathrm{Ni}, \mathrm{Cu}, \\
\mathrm{Sn}\end{array}$ & - & - & - & $\mathrm{Ga}$ & - & - & - \\
\hline $\mathrm{Li}(\mathrm{ug} / \mathrm{L})$ & $\mathrm{Ce}$ & - & $\mathrm{Al}$ & - & $\mathrm{Co}, \mathrm{Zn}, \mathrm{Sr}$ & - & - & - \\
\hline $\mathrm{Be}(\mathrm{ug} / \mathrm{L})$ & $\mathrm{Al}$ & & & & & & & \\
\hline $\mathrm{Sc}(\mathrm{ug} / \mathrm{L})$ & $\mathrm{Ba}$ & - & $\mathrm{U}, \mathrm{Si}$ & - & - & - & - & - \\
\hline $\mathrm{Ti}$ (ug/L) & $\mathrm{Cu}, \mathrm{Cs}, \mathrm{Th}$ & - & $\mathrm{Ni}, \mathrm{Mn}, \mathrm{V}$ & - & $\mathrm{Ga}, \mathrm{Sn}, \mathrm{Pb}$ & - & - & - \\
\hline $\mathrm{Cr}(\mathrm{ug} / \mathrm{L})$ & - & - & $\mathrm{Ga}, \mathrm{Mn}$ & - & $\begin{array}{c}\mathrm{Co}, \mathrm{Ni}, \mathrm{Sr}, \mathrm{Sn}, \\
\mathrm{Pb}, \mathrm{Al}, \mathrm{Fe}\end{array}$ & - & - & - \\
\hline Co (ug/L) & $\mathrm{Ga}, \mathrm{Sn}$ & - & $\mathrm{Pb}, \mathrm{Ce}, \mathrm{Mn}$ & - & $\mathrm{Ni}, \mathrm{Sr}, \mathrm{Al}$ & - & - & - \\
\hline $\mathrm{Ni}(\mathrm{ug} / \mathrm{L})$ & $\mathrm{Al}, \mathrm{Fe}$ & - & $\mathrm{Cu}, \mathrm{Mn}, \mathrm{V}$ & - & $\mathrm{Sn}, \mathrm{Ce}$ & - & $\mathrm{Pb}, \mathrm{Ga}$ & - \\
\hline $\mathrm{Cu}(\mathrm{ug} / \mathrm{L})$ & $\mathrm{Pb}$ & - & $\mathrm{Sn}$ & - & $\mathrm{Ga}$ & - & - & - \\
\hline $\mathrm{Ga}(\mathrm{ug} / \mathrm{L})$ & $\mathrm{Al}, \mathrm{Fe}$ & $\mathrm{Ce}$ & - & - & $\mathrm{Pb}$ & - & $\mathrm{Sn}$ & - \\
\hline Ge (ug/L) & - & - & - & - & $\mathrm{Se}, \mathrm{Y}, \mathrm{La}$ & - & $\operatorname{Pr}$ & - \\
\hline $\mathrm{Se}(\mathrm{ug} / \mathrm{L})$ & - & - & - & - & $\mathrm{La}$ & - & $\mathrm{Y}, \mathrm{Pr}$ & - \\
\hline $\mathrm{Rb}(\mathrm{ug} / \mathrm{L})$ & - & - & Cs & - & - & - & - & - \\
\hline $\mathrm{Sr}$ (ug/L) & - & - & - & - & $\mathrm{Al}$ & - & - & - \\
\hline Y (ug/L) & - & - & - & - & $\mathrm{La}, \mathrm{Pr}$ & - & - & - \\
\hline Sn (ug/L) & - & $\mathrm{Al}, \mathrm{V}$ & $\mathrm{Mn}$ & - & $\mathrm{Fe}$ & - & $\mathrm{Pb}$ & - \\
\hline $\mathrm{Ba}(\mathrm{ug} / \mathrm{L})$ & $\mathrm{V}$ & - & - & - & $\mathrm{Si}$ & - & - & - \\
\hline $\mathrm{Pb}(\mathrm{ug} / \mathrm{L})$ & - & $\mathrm{Ce}$ & $\mathrm{Al}, \mathrm{Fe}$ & - & $\mathrm{Mn}, \mathrm{V}$ & - & - & - \\
\hline $\mathrm{La}(\mathrm{ug} / \mathrm{L})$ & - & - & - & - & $\operatorname{Pr}$ & - & - & - \\
\hline $\mathrm{Si}(\mathrm{mg} / \mathrm{L})$ & $\mathrm{V}$ & & & & & & & \\
\hline $\mathrm{Fe}(\mathrm{mg} / \mathrm{L})$ & - & - & $\mathrm{V}$ & - & - & - & $\mathrm{Mn}$ & - \\
\hline $\mathrm{Mn}(\mathrm{mg} / \mathrm{L})$ & - & - & $\mathrm{V}$ & - & - & - & - & - \\
\hline
\end{tabular}

Obs.: (1) p<0,05 - limite aceitável de erro, ou probabilidade de que 5\% dos resultados de correlação sejam casuais.

(2) somente o íon cloreto não possuiu alguma correlação com os demais parâmetros analisados. 
Correlações significativas $\quad\left(\mathrm{R}^{2}>0,80\right)$ também são apresentadas na Tabela 8 , tais como a profundidade com os elementos cromo, cobalto, níquel, estrôncio, estanho e chumbo (correlações negativas) e fluoreto (positiva), Eh com cálcio, estrôncio e alumínio (positiva) e com potássio (negativa), cálcio com magnésio (positiva), sódio e brometo (positiva). O elemento Sulfato correlaciona-se com gálio (positiva), o lítio com cobalto e estrôncio (correlações positivas), titânio com gálio, estanho, chumbo, cobalto, níquel, estrôncio (correlações positivas), cromo correlaciona-se com estanho, chumbo, alumínio e ferro (positivas), o cobalto com níquel, estrôncio e aluminio (positivas), níquel com estanho e cério (positivas), cobre com gálio (positiva), gálio com chumbo (positiva), selênio com lantânio (positiva), estrôncio com alumínio (positiva), ítrio com praseodímio (correlação positiva), estanho e ferro (positiva), bário e silício (positiva), chumbo com manganês (positiva) e lantânio e praseodímio (positiva).

\section{DISCUSSÃO}

Os resultados dos lixiviados apresentam comportamentos muito significativos, uma vez que permitiram identificar os elementos prontamente solúveis e seus comportamentos ao longo do perfil de alteração. Assim, os elementos lixiviados em solo contaminado por vinhaça apresentaram diferentes comportamentos em relação à profundidade. As características texturais do solo indicaram uma maior percentagem de argila em menores profundidades do perfil. No entanto, essas argilas se encontram floculadas, fato que permitiu maior infiltração da vinhaça ou soluções no perfil do solo, uma vez que com a floculação das argilas, o solo passa a apresentar predominância de frações siltes e areias finas, e, portanto maiores permeabilidades. Os estudos relativos ao comportamento de elementos químicos em solos contaminados por vinhaça geralmente focam o solo agriculturável, ou seja, profundidades inferiores a um metro. Nesse contexto, estudos foram realizados em ensaios de coluna em 3 tipos de solo (Nitossolo, Argissolo e Espodossolo) (BRITO et al. 2007). Os resultados mostraram diferenciações nos lixiviados, porém em todos os solos houve aumento de concentração de potássio e diminuição de sódio. Outro estudo avaliou o efeito poluente da vinhaça que sofreu infiltração em canal condutor de terra em até 1,5 metros de profundidade em São João da Boa Vista, São Paulo (LUDOVICE, 1997). A autora verificou a alteração das características de $\mathrm{pH}$, condutivida- de elétrica, Demanda Bioquímica de Oxigênio (DBO), nitrogênio amoniacal, nitrato, nitrito e Kjedahl, de soluções provenientes da vinhaça percolada em solo areno-siltoso nestes canais condutores. Estudo realizado pela Companhia de Tecnologia e Saneamento Ambiental (CETESB, 1994) em tanques de armazenamento de diversas usinas comprovou a contaminação deste efluente nas águas subterrâneas, com o aumento dos valores de condutividade elétrica, cloreto, nitrogênio amoniacal e potássio, considerado como elemento traçador da presença de vinhaça no estudo. Este estudo ainda avaliou o comportamento do elemento Cálcio e Magnésio, que se concentraram nas primeiras camadas de solo; o pH aumentou ao longo do perfil pelo consumo de íons hidrogênio na reação de redução de Ferro Férrico para Ferro Ferroso. Em relação ao Sulfato, não apresentou comportamento esperado, talvez devido ao $\mathrm{pH}$ do solo não ter atingido a extrema redução. $\mathrm{O}$ aumento significativo do $\mathrm{pH}$ em profundidade no presente estudo pode ser explicada pela: (1) a introdução de cátions básicos pela vinhaça, (2) o decréscimo do potencial de oxirredução, causando a redução dos óxidos, hidróxidos ou hidróxidos de ferro e manganês, e por fim (3) a atividade microbiológica (NUNES et al., 1981).

Estudos realizados na década de 1980 (CAMARGO et al., 1987; CARDOSO, 1988, NUNES et al., 1981; ORLANDO FILHO et al., 1983) observaram aumento significativo em solo das concentrações de Cálcio, Magnésio e principalmente de Potássio, que estão em grandes quantidades na vinhaça; o aumento desses elementos em profundidade é decorrente da intensa lixiviação com o aporte deste efluente.

O comportamento físico químico de solos em profundidade em áreas de sacrifício foi estudado, com amostragens desde 0,2 metros a até 5,5 metros de profundidade (próximo ao nível freático) (HASSUDA, 1989). Houve um aumento de $\mathrm{pH}$ ao longo do perfil de solo, de Potássio e Sódio; os elementos Cálcio, Magnésio, Nitrato e Amônio apresentaram valores baixos nos primeiros centímetros de profundidade, um aumento entre $1,0 \mathrm{e}$ 4,0 metros e redução de concentrações desses elementos próximos ao nível d'água. Os elementos Fósforo, Ferro Ferroso, Manganês e Zinco possuíram uma alta concentração nos primeiros centímetros de profundidade, uma redução entre 1 e 4 metros e tendência de aumento na proximidade da zona saturada. Houve um ligeiro aumento de condutividade elétrica ao longo do perfil e redução próxima ao nível freático. De acordo com este 
autor, a infiltração de vinhaça aumenta o $\mathrm{pH}$, que de ácido vai se tornando neutro a medida que os íons hidrogênio e Alumínio que se encontram adsorvidos são deslocados pelas bases principais (Potássio, Cálcio, Magnésio e Sódio) presentes na vinhaça (HASSUDA, 1989). Assim, há o enriquecimento dos íons hidrogênio e Alumínio na solução. Em relação aos íons Sódio, Magnésio, Cálcio, Hidrogênio e Alumínio, os processos de troca iônica e adsorção atuam no maior enriquecimento desses elementos na zona não saturada, que por sua vez são controlados pelo $\mathrm{pH}$ de equilíbrio da solução do solo (HASSUDA, 1989). Assim o pH do solo foi favorável à adsorção dos cátions devido a matéria orgânica da vinhaça e do Ferro das camadas limoníticas do solo.

No presente estudo, a relação pH e Eh indica uma modificação de ambientes ao longo do perfil, oxidante até a profundidade aproximada de 11 metros e com características redutoras até 24 metros, observada também pela mudança de coloração do material de alteração coletado.

As concentrações dos elementos químicos, como $\mathrm{Cr}, \mathrm{Co}, \mathrm{Ni}, \mathrm{Sr}, \mathrm{Sn}, \mathrm{Pb}$ (com r > -0,80 em relação a profundidade), e $\mathrm{Li}, \mathrm{Sc}, \mathrm{Ti}, \mathrm{Cu}, \mathrm{Zn}, \mathrm{Ga}, \mathrm{Bi}$ e $\mathrm{Ce}$ ( $\mathrm{r}>$ $-0,75$ ) decrescem ao longo do perfil, bem como elementos de maior concentração como Nitrato e Sulfato. Os elementos $\mathrm{Cr}, \mathrm{Co}, \mathrm{Ni}, \mathrm{Sr}, \mathrm{Sn}, \mathrm{Pb}, \mathrm{Li}, \mathrm{Sc}$, $\mathrm{Ti}, \mathrm{Cu}, \mathrm{Zn}, \mathrm{Ga}, \mathrm{Bi}$ e Ce são adsorvidos nas profundidades mais rasas pela presença de matéria orgânica e podem ser lixiviados para a solução devido a acidez da vinhaça que é infiltrada (que possui pH ácido). No caso do Nitrato e Sulfato, devido às mudanças das condições de oxirredução, podem ter se transformado para Sulfeto e Amônio, formas mais redutoras. No caso do Nitrogênio, os valores de Amônio não foram inclusos nos resultados, pois, apresentaram contaminação cruzada deste elemento. No entanto pode-se reportar a presença deste íon na água, principalmente entre as profundidades de 6 a 19 metros, e Nitrato entre 1 a 8 metros. O Sulfato ocorre entre 1 a 11 metros e decai a baixas concentrações até a profundidade de saturação do perfil. As modificações de $\mathrm{pH}$ e Eh pode reduzir o Sulfato a Sulfeto, com colaboração dos microorganismos existentes no solo.

O íon Fluoreto apresenta correlação positiva com a profundidade, uma vez que esse elemento possui mobilidade elevada em ambientes neutros a básicos (DISSANAYAKE e CHANDRAJITH, 1999).

Destacam-se sete fatores que controlam a concentração deste elemento em águas naturais: a temperatura, o pH, íons e colóides complexantes, solubilidade de minerais com flúor, facilidade de troca iônica com $\mathrm{OH}^{-}$, tamanho e tipo de formações geológicas (APAMBIRE et al., 1997). Neste caso, o pH e o Eh são os parâmetros mais correlacionáveis ao comportamento do fluoreto nos lixiviados.
O comportamento de Alumínio (decrescente com a profundidade) pode estar associado à complexação com os componentes orgânicos da vinhaça (na forma coloidal) como também a neutralização do cátion Hidrogênio do solo pelas cargas negativas de grupos funcionais da matéria orgânica (CAMARGO et al., 1983; CARDOSO, 1988; MAZZA, 1985; NUNES et al., 1981; RIBEIRO e SENGIK, 1983; SANTOS et al., 1981). Ainda, a precipitação de Alumínio pode ser causada por processos microbiológicos de redução, quando o $\mathrm{pH}$ elevaria a mais de $5,5 \mathrm{~m}$.

\section{CONCLUSÕES}

$\mathrm{O}$ estudo do lixiviado permitiu avaliar o comportamento de águas de infiltração ao longo do perfil de solo contaminado de vinhaça. Os resultados das análises foram corroborados com a literatura existente sobre a relação da liberação de elementos solúveis para o lixiviado e seu ambiente de oxirredução.

O método proposto por Hageman (2007) é mais simples que os demais métodos de lixiviação e seus resultados foram satisfatórios aos objetivos do presente artigo, principalmente para análise química dos elementos maiores e menores por cromatografia iônica.

O tratamento estatístico por correlação Pearson-r foi instrumento útil para a análise do comportamento dos elementos neste perfil de solo, pois se definiu elementos com grandes afinidades entre si, assim como sua elevada correlação com a profundidade e o ambiente encontrado.

A presença de vinhaça ao longo do perfil do solo pode ser atribuída à elevada concentração de Sódio e Cálcio, bem como na concentração anômala de Potássio, que é lixiviada com o aumento de concentração em profundidade. $\mathrm{O}$ aumento da concentração do Potássio em profundidade pode indicar o alcance da infiltração da vinhaça em subsuperfície e nas águas subterrâneas.

$\mathrm{O}$ ambiente de oxidação compreende o intervalo de profundidade de 0 a 10 metros, e é representado pela coloração avermelhada do solo e o ambiente reduzido, a partir de 10 metros de profundidade, é representado pela cor cinza amarelado dos sedimentos mais profundos. Esta mudança de ambiente é relacionada à variação da distribuição das concentrações de elementos como Fluoreto, Sulfato, Nitrato, e metais do lixiviado. As presenças de argila, e principalmente da matéria orgânica e de óxidos de Ferro, situadas nas menores profundidades do perfil, adsorvem os elementos traços; devido ao grande volume infiltrado de vinhaça ao longo dos anos neste nível uma grande concentração de elementos lixiviados foi identificada. 
Por fim destacam-se os comportamentos similares de metais - traço em lixiviados, com correlação $r \leq 0,90$, entre: Sódio e Nitrato, Níquel,
Chumbo e Gálio, Gálio e Estanho, Germânio e Praseodímio, Selênio, Ítrio e Praseodímio, Estanho e Chumbo, e Ferro e Manganês.

\section{AGRADECIMENTOS}

Os autores gostariam de deixar registrados os mais sinceros agradecimentos para Fapesp, processo n²007/05323-1, pelo suporte a pesquisa; ao Núcleo Dandara do Assentamento Sepé Tiaraju, na pessoa de seu coordenador, o Sr. Elias Hemis Lopes pela permissão e auxilio nos trabalhos de campo, ao INCRA (Instituto Nacional de Colonização e Reforma Agrária) e ao corpo de funcionários, representados pelo Sr Elcio Marinho, do Instituto de Geociências pelo suporte de infraestrutura e logística.

\section{REFERÊNCIAS}

ASSOCIAÇÃO BRASILEIRA DE NORMAS TÉCNICAS. NBR 8604/1986 - Abertura de poço e trincheira de inspeção em solo, com retirada de amostras deformadas e indeformadas (procedimentos). 1986.

NBR 7181 - Análise granulométrica, 1984.

APAMBIRE, W.B.; BOYLE, D.R.; MICHEL, F.A. Geochemistry, genesis and health implications of fluoriferous groundwaters in the upper regions of Ghana. Environmental Geology. Berlin, v. 33, n.1, p. 13-24, 1997.

BRITO, F.L.; ROLIM, M.M.; SILVA, J.A.A.; PEDROSA, E.M.R. 2007. Qualidade do percolado de solos que receberam vinhaça em diferentes doses e tempo de incubação. Revista Bras. Eng. Agric. Ambiental. Campina Grande. v.11, n.3, p. 318-313, 2007.

CAMARGO. O.A. DE; VALADARES, J.M.A. DA S.; GERALDINI, R.N. Características químicas e físicas de solo que recebeu vinhaça por longo tempo. Bol. Tecn. Inst. Agron. Campinas. Campinas, n.76, p. 1-29, 1983.

CAMARGO. O.A. DE; VALADARES, J.M.A. DA S.; BERTON, R.S.; TEÓFILO SOBRINHO, J.; MENK, J.R.F. 1987. Alteração das características químicas de um Latossolo Vermelho-Escuro Distrófico pela aplicação de vinhaça. Bol. Cient. Inst. Agron. Campinas, n. 9. p.1-23, 1987.

CARDOSO, A.N. Influência da aplicação de vinhaça em propriedades físicas e químicas de um Latossolo Vermelho-Escuro Álico fase cerrado. Viçosa, Minas Gerais, Brasil. 1988. 73 p. Dissertação (Mestrado em Agronomia). Universidade Federal de Viçosa, 1988.

Companhia de Tecnologia de Saneamento Ambiental - CETESB. Poluição do solo e aquifero subterrâneo pela vinhaça infiltrada sob tanques de armazenamento. Relatório técnico, São Paulo, 1994. 31 p.

CORTEZ, L.; FREIRE, W.J.; ROSILLO-CALLE, F. Biodigestion of vinasse in Brazil. Int. Sugar Journal. New Orleans, Louisiana, USA. v. 100, n. 1196, p. 403-413, 1998.

DISSANAYAKE, C.B.; CHANDRAJITH, R. Medical geology of tropical environments. Earth-Science Reviews, v. 47, p. 219-258, 1999

GLOEDEN, E.; CUNHA, R.C.A.; FRACCAROLI, M.J.B.; CLEARY, R.W. The behaviour of vinasse constituents in the unsaturated and saturated zones in the Botucatu Aquifer recharge area. Water Sciences Technology, London. UK, v. 24, n 11.p. 147-157, 1991

HAGEMAN, P.L. U.S. Geological Survey Field Leach test for assessing water reactivity and leaching potential of mines wastes, soils and other geologic and environmental materials. U.S. Geological Survey Techniques and Methods. Reston, Virginia, USA, book 5, chapter D3. P 1-14. 2007.

HASSUDA, S. Impactos da infiltração da vinhaça de cana no Aquifero Bauru. São Paulo, Brasil. 1989. 92 p. Dissertação (Mestrado em Hidrogeologia). São Paulo, 1989.

LUDOVICE, M.T.F. Estudo do efeito poluente da vinhaça infiltrada em canal condutor de terra sobre o lençol freático. Campinas, São Paulo, Brasil, 1997. 117 p. Dissertação (Mestrado em Engenharia Civil). Universidade Estadual de Campinas. Campinas, SP, 1997.

MAZZA, J.A. Variações em algumas propriedades de solos com cana de açúcar (Saccharum spp), tratados com doses maciças de vinhaça. Piracicaba, São Paulo, Brasil. 1985. 104 p. Dissertação (Mestrado em Agronomia). Universidade de São Paulo. São Paulo, 1985.

MASON, B.H. Princípios de geoquímica. São Paulo:. Ed. Poligono - USP, 1971.

NODSTROM, D.K.; WILDE, F.D. 1998. Reduction-oxidation potential (electrode method). IN: WILDE, F.D.; RADTKE, D.B.; GIBS, J.; IWATSUBO, R.T. (Eds.). National field manual for the collection of water - quality data: Field measurements. USGS - TWRI, p 3-20. Disponível em: <http://pubs.water.usgs.gov/twri/wri9A6/> . Acesso em: 18 fev. 2011.

NUNES, M.R.; VELLOSO, A.C.X.; LEAL, J.R. Efeito da Vinhaça nos cátions trocáveis e outros elementos químicos do solo. Pesq. Agropec. Bras. Brasília, Brasil, v.16, n. 2, p. 171176, 1981.

ORLANDO FILHO, J.; ZAMBELLO JR., E.; AGUJARD, R.; ROSSETTO, A.J. Efeito da aplicação prolongada da vinhaça nas propriedades químicas dos solos com cana-de-açúcar. Estudo exploratório. STAB-Açúcar Alcool e Subprodutos. Piracicaba, São Paulo, Brasil, v. 1, p. 28-33, 1983.

POTTS, P.J. A Handbook of Silicate Rock Analysis. 2 ed. London, Glasgow. 1992. 
PEREIRA, S.Y.; ARCARO, N. P.; MORTATTI, B.C.; MIGUEL, M.G.

REZENDE, J.O. Vinhaça: outra grande ameaça ao meio ambiente. Revista Magistra, UFBA, v.1, 1984.

RIBEIRO, A.C.; SENGIK, E. Efeitos da aplicação de vinhaça nas propriedades físicas e químicas de duas amostras de latossolos. Revista Ceres, Viçosa, Minas Gerais, Brasil, v. 30, p. 25-31, 1983.
SANTOS, G.A.; ROSSIELO, R.O.P.; FERNANDES, M.S.; O’GRADY, P.C. Efeitos da vinhaça sobre o pH do solo, e germinação e o acúmulo de potássio em milho. Pesq. Agropec. Bra. Brasília, Brasil, v. 16, p. 489-493, 1981. 